Spring 4-5-2021

\title{
Reducing Stroke Readmission Through the Implementation of Telehealth
}

Leilani Hermosura

University of St. Augustine for Health Sciences, I.hermosurabautista@usa.edu

DOI: https://doi.org/10.46409/sr.KKTK3774

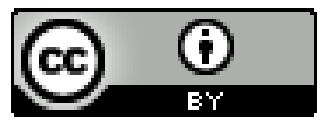

This work is licensed under a Creative Commons Attribution 4.0 License.

Follow this and additional works at: https://soar.usa.edu/scholprojects

Part of the Health Information Technology Commons, and the Rehabilitation and Therapy Commons

\section{Recommended Citation}

Hermosura, L. (2021). Reducing Stroke Readmission Through the Implementation of Telehealth. [Doctoral project, University of St Augustine for Health Sciences]. SOAR @ USA: Student Scholarly Projects Collection. https://doi.org/10.46409/sr.KKTK3774

This Scholarly Project is brought to you for free and open access by the Student Research at SOAR @ USA. It has been accepted for inclusion in Student Scholarly Projects by an authorized administrator of SOAR @ USA. For more information, please contact soar@usa.edu, erobinson@usa.edu. 
Reducing Stroke Readmission through the Implementation of

\section{Telehealth}

Leilani Hermosura Bautista, MSN, FNP

School of Nursing, University of St. Augustine for Health Sciences

This Manuscript Partially Fulfills the Requirements for the

Doctor of Nursing Practice Program and is Approved by:

Course Faculty: Sue Bingham, PhD

Preceptor: Michelle Sterling, DNP

Date of Final Approval written as: April 5, 2021 


\begin{abstract}
Practice Problem: Readmission occurs frequently among patients with stroke and because of this, the Centers for Medicare and Medicaid Services (CMS) have imposed programs to reduce 30-day readmissions among hospitals. The health care system must respond with transition of care, especially during the period of recent stroke to improve patient outcomes.
\end{abstract}

PICOT: The PICOT question that guided this project was among patients with a recent diagnosis of stroke $(\mathrm{P})$, what is the effect of a telehealth appointment with a nurse practitioner (NP) for post discharge follow-up (I), compared to a standard face-to-face clinic appointment (C), on 30-day readmissions rates $(\mathrm{O})$, within two months $(\mathrm{T})$ ?

Evidence: Stroke is the fourth leading cause of death and has a readmission rate of $14 \%$. Past studies have demonstrated the effectiveness of telehealth in treating patients outside of the hospital setting, which suggests the potential of telehealth on post-discharge follow-up care.

Intervention: To assess the impact of telehealth on 30-day readmission rates, stroke patients received a telehealth follow-up phone visit by a NP within ten days of being discharged to home.

Outcome: Data was collected from participant's electronic health records (EHR) and discharge databases from October 13 to November 13, 2020. Among participants, the implementation of telehealth visits demonstrated a reduced readmission rate of $6.25 \%$ for stroke patients.

Conclusion: Telehealth is an effective, sustainable, and widely implementable strategy to provide post-discharge care to patients. This study outlined a framework to further analyze the effectiveness of telehealth visits in reducing 30-day readmission rates among stroke patients. 


\section{Reducing Stroke Readmission Using Telehealth}

Healthy People 2020 strives to address the lack of access to healthcare, particularly among certain populations challenged by lack of insurance, cost, cultural competence, proximity to hospitals, and other social issues posing barriers to access (Healthy People 2020, 2019). The inability to readily access healthcare creates a foundation for negative outcomes impacting the rate of recovery, quality of life, and financial strain on hospitals that manage such populations. Programs developed by the Centers for Medicare and Medicaid Services (CMS) such as the Hospital Readmissions Reduction Program (HRRP), which aim to improve quality by impacting reimbursement rates for hospitals with high 30-day readmission rates, further impose strain among hospitals. Recent events created an increased demand to connect with patients using telehealth by bringing access to medical care wherever the patient is located (Serper \& Volk, 2018). The purpose of this evidence-based practice (EBP) project was to illustrate the implementation of telehealth in the outpatient care setting as a modality to increase access to care among patients who recently sustained a stroke and to reduce readmission rate within 30-days post discharge. This project previewed EBP and literature review to support the use of telehealth among stroke populations and identified a theoretical framework to support the implementation of a successful change project. This paper discussed evidence search strategies used and findings for common themes. The practice setting, overview, recommendation, methodology, and evaluation were also included with a plan for project dissemination.

\section{Significance of the Practice Problem}

Readmission rates represent a key quality indicator of healthcare services (Fisher et al., 2014). In the United States (US), avoidance of 30-day readmission is a top priority because of HRRP and federal guidelines under the Affordable Care Act of 2010 (Gai \& Pachamanova, 
2019). Measurement of 30-day readmission to assess the quality of care was also a recommendation by the Agency of Healthcare Research and Quality (AHRQ) in the United States (Ross et al., 2017). Hospitals received financial penalties if they demonstrate high recurrence of 30-day readmission rates (Vahidy et al., 2017).

Readmission occurs frequently among stroke survivors (The Global Burden Disease [GBD] Lifetime Risk of Stroke Collaborators, 2016). In the past, stroke has been a leading diagnosis in readmission accounting for $25 \%$ of incidents during the first year of diagnosis (Gorelick, 2019). Poston (2018) found a 12\% unplanned readmission within one month of discharge among patients with ischemic stroke. According to California Health and Human Services (CHHS), the national readmission rate is $14 \%$ for stroke patients, thus, these readmissions resulted in a cost of about 500 million dollars to CMS (Gorelick, 2019). Unplanned readmissions among patients with stroke happen due to various medical reasons one-month postdischarge such as kidney and urinary infection, pneumonia, health failure, and electrolyte imbalances (Nouh et al., 2017). Readmission is also attributed to patients missing their follow up appointments due to debility and fatigue after hospitalization (Boehmn et al, 2015). With a movement towards shortened length of hospitalization, patients with stroke are discharged with limited inpatient rehabilitation programs (Hicks \& Cimarolli, 2018). Stroke is a debilitating event requiring close medical follow up to mitigate further complications (Driessen et al., 2016).

Globally, stroke incidence affects 15 million patients annually and represents the second largest cause of death following heart disease (Gorelick, 2019). According to the GBD study in 2016, stroke is the leading cause of disability worldwide with approximately 80 million survivors requiring post stroke care (World health Organization [WHO], 2018). Five million people 
worldwide live with permanent disabilities from stroke (World Stroke Organization [WSO], 2016).

Nationally, stroke comprises the fourth leading cause of death (Center for Disease Control [CDC], 2018). Annual statistics in the US show approximately 800,000 American adults have suffered from a stroke (WSO, 2016). The estimated cost of healthcare services, medicines to treat stroke, and missed days of work is estimated at \$34 billion annually (CDC, 2019).

Locally, the incidence of stroke is $80-90$ people per 100,000. As part of a complex Los Angeles health care system, the identified health care agency directs a stroke system of care that manages stroke patients for both acute and rehabilitation needs. This safety net facility houses an inpatient stroke unit with 24 beds, sees an average of six discharges per week, and operates an outpatient medical home service with 120 unique patients served weekly (Rancho, n.d.). In comparison to the national readmission data, the Los Angeles health care system has an $18 \%$ readmission rate for patients with stroke who generally endure socio-economic disadvantages, such as lack of financial support to arrange for a clinic transportation or lack of familial support (Lacounty.gov). Patients with stroke are burdened with the sequela of long-term disability impacting mobility, loss of independence, income, or employment, with a lifetime cost of stroke per person of $\$ 105,000$ (Johnson, Bonafede, \& Watson, 2016; Terman et al., 2018). The average cost of hospitalization involving stroke is $\$ 23,000$ and varies greatly by the type of stroke, diagnosis status, and co-morbidites, such as hypertension or diabetes (Wang et al., 2013). The health care system must respond with transition care, especially during the period of recent stroke, and complex care needs further complicate stroke-related disabilities (Terman et al., 2018). Providing telehealth as a follow up intervention after discharge offers a way to reduce readmission among patients with stroke (Hicks \& Cimarolli, 2018). 


\section{PICOT Question}

The PICOT question that will be addressed is: Among patients with a recent diagnosis of stroke $(\mathrm{P})$, what is the effect of a telehealth appointment with a nurse practitioner (NP) for post discharge follow-up (I), compared to a standard face-to-face clinic appointment (C), on 30-day readmissions rates $(\mathrm{O})$, within two months $(\mathrm{T})$ ?

The population selected was composed of adult patients recently diagnosed with a stroke resulting in a physical impairment. These patients were offered a telehealth encounter with the NP within two weeks of being discharged from the hospital instead of the standard practice of a face-to-face clinic appointment to address concerns since hospitalization. The patient was given a time and date when telehealth will transpire. The facility has a standard practice to give patients a post-discharge follow-up with a 40-minute appointment to complete the encounter. CMS requires a transition of care process be in place to account for patients after they are discharged. This may include care coordination with a registered nurse $(\mathrm{RN})$ to manage the patient after discharge, such as reviewing medications adherence (Poston, 2018). As an outcome, the practice change explores the adaptation of telehealth phone visits to increase access to care outside of a clinic setting (Henderson, Davis, Smith \& King, 2014). With the use of telehealth, the NP can address patients' concerns and deliver just-in-time care, which may avoid readmission to the hospital (Poston, 2018). The timing of the project will evaluate the impact of using telehealth phone visits on reducing readmission within sixty days after the implementation of the practice change.

\section{Theoretical Framework and Change Theory}

The evidence-based practice (EBP) frameworks and theories are used to explain how a telehealth phone visit is an intervention for following up with patients post stroke. Telehealth 
nursing renders a chance to transform the art of caring and healing (Caroll, 2018). In describing the NP practice, interaction between the patient and the NP in the clinical setting focuses on identifying patient goals and agreeing on a plan to accomplish set goals (Henderson, Davis, Smith, \& King, 2014). The nursing profession embraces EBPs urging the use of evidence-based research to support their decisions in the clinical setting and to improve patient outcomes (Doody \& Doody, 2013). The seven-step EPB model, known as the Iowa model, gives guidance in identifying an issue in the practice setting and identifying interventions supported by literature that are evidence-based in pursuit of change in nursing practice (Brown, 2014). The first three steps involve identifying a focused problem, prioritizing the problem within an organization, and assembling an interdisciplinary team to develop, implement, and evaluate EBP change. Steps four and five involve gathering, evaluating, and critiquing relevant studies that support the PICOT question. Step six involved pilot implementation in a practice setting and full EBP implementation based on evaluations made by the interdisciplinary team. The last step in the Iowa model focuses on continued monitoring and analysis of the project outcome. With use of Iowa Model, one gains awareness on introducing, developing, and evaluating EBP from an evidence-based perspective (Brown, 2014).

Kotter's process of leading change offers an applicable change model for implementation in telehealth appointments. A process for leading change, Kotter's model is a credible and teachable process which clarifies potential misunderstandings that may create resistance (Reineck, 2007). Additionally, it provides guidance to leadership for planned changes (Smith, 2007). Implementation of telehealth is anticipated by the organization to mitigate patient barriers that lead to broken appointment rates, such as lack of transportation and new medical impairments from stroke. As the organization implements the use of telehealth, data is provided 
weekly at medical staff meetings regarding impact to access, patient satisfaction, and improved patient outcomes. Project change success will be shared and presented to other clinical specialties, such as those involving spinal cord injury and behavioral health. The practice change has been implemented and extended to other services and telehealth is now institutionalized.

\section{Evidence Search Strategy}

In support of the PICOT question, a search strategy used Cumulative Index to Nursing and Allied Health Literature (CINAHL), PubMed, Dynamed Plus, and Cochrane Library from 2015 to 2020 to obtain high quality, evidence-based literature on the implementation of telehealth. Keywords and medical headings included stroke, cerebrovascular accident, adult patients, post stroke, readmission, nursing, and telemedicine. Controlled or feasibility trials included an intervention group receiving tele-rehabilitation for stroke survivors, compared with a control group on standard of care. The inclusion criteria were most of the keywords and articles published in the United States from years 2015-2020. The exclusion criteria included no reference in using telehealth, non-stroke population, application to home health or case management, and no reference to admission. Of 425 articles, only 29 non-duplicated citations were eligible based criteria set, English language, and title and abstract review. CINAHL showed 17 relevant articles, PubMed showed three relevant articles, Dynamed Plus had seven, and Cochrane Library had two relevant articles. After screening for full text review, ten studies fulfilled the predefined inclusion criteria based on (1) participation of nurse and other healthcare professionals, (2) application to stroke population, (3) impact of telehealth as an intervention, and (4) any impact or reference to stroke readmission.

Reviewed articles reported improved patient outcomes after integration of telehealth to their medical care outside of the hospital setting and reduction or avoidance of hospital 
readmissions (Van den Berg, et al., 2016; Driessen, et al., 2016; Linder, et al., 2015). Studies utilized NPs in implementing telehealth for their patients and respective settings (Linder, et al, 2015; Collier, et al., 2015). Evidence based strategies were organized based on the outcomes of impact on readmission, and applicability of telehealth in the delivery of care among stroke patients.

\section{Evidence Search Results and Evaluation}

To gather scholarly work on EBPs supporting the implementation of telehealth encounters for patients with recent diagnosis of stroke, a systematic review and electronic search of digital databases from the library of University of St Augustine (USA) Health Sciences revealed ten relevant works to support the PICOT question. Most of the database search utilized CINAHL, PubMed, and Dynamed Plus. An electronic search of NP under journal finder in the USA Library was also performed.

For all the databases, the headings and keywords used were stroke, telehealth, rehabilitation, 30-day readmissions, nursing, and application to healthcare. To expand the search for supporting documents, other related articles were reviewed based on the references listed. Inclusion criteria for all the databases and article search used most of the keywords, full text, English only, and years of publication in 2015-2020. The search resulted with citations as follows: CINAHL 17 citations, PubMed three citations, Dynamed Plus seven citations, and Cochrane Library two citations. Initially, the Journal search of NP did not match most of the keywords required to be useful in addressing the PICOT question. A total of 29 non-duplicated articles proved useful as references. All the 29 abstracts and titles were strategically reviewed and screened based on reference to stroke group, use of telehealth, and readmission. 
After this initial review, nine articles were excluded based on the following: (1) absence of direct reference to use of telehealth, (2) population studied were cardiac patients with CHF, (3) application to case management and home health services, and (4) lack or no reference to readmissions. The remaining unduplicated twenty articles were reviewed as full text to determine the usefulness and relevance to the PICOT question. The result of search for research evidence yielded ten scholarly articles shown as a Prisma diagram (see Figure 1).

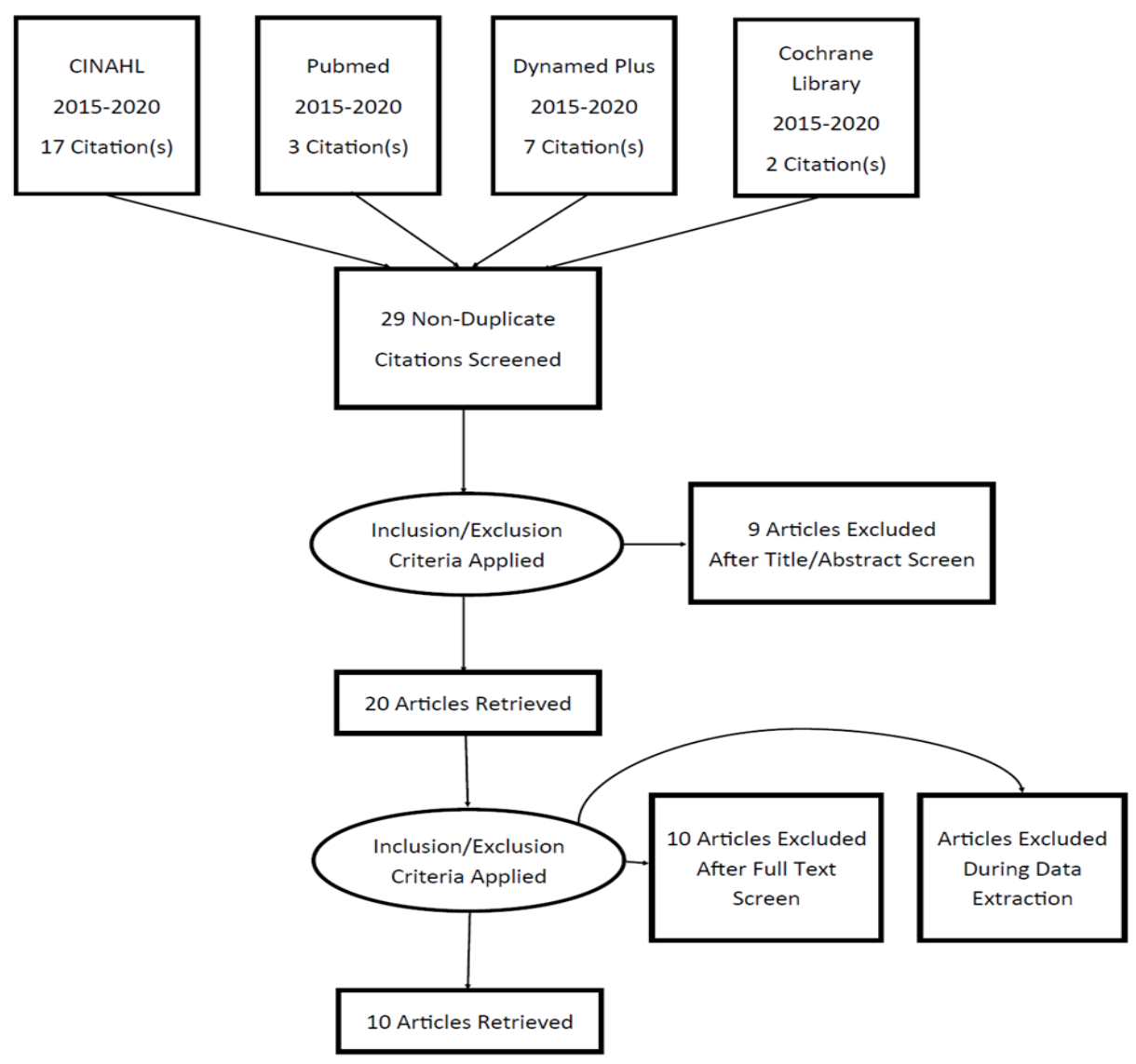

\section{Figure 1: Results of Search for Research Evidence}

Most articles referred to the use of telehealth intervention and referenced 30-day readmission. The EBP change project was supported by the articles selected that focused on the use of a telehealth intervention. Based on all the findings, the strength of recommendation was at 
level A on the Strength of Recommendation Taxonomy on consistent and good quality patientoriented evidence (Ebell et al., 2004).

\section{Themes from the Evidence}

A synthesis of the literature was appropriate to gain a better insight on the components of the PICOT question. This synthesis consisted of ten articles as follows: 7 qualitative (Bambhroliya, et al., 2018; Nouh, et al., 2017; Vahidy, et al., 2017; O’Connor, et al., 2016; Drissen, et al., 2016; Collier, et al., 2015; Strowd, Wise, \& Umei, 2014) and 3 quantitative (Rosen, McCall, \& Primack, 2017; Van den Berg, et al., 2016; Linder, Rosenfeldt, Bay, Sahu, \& Wolf, 2015). These articles revealed major ideas for exploring telehealth as an innovative way to deliver healthcare and its impact in reducing 30-day readmission. A table of the summary of primary research evidence is provided (see Appendix A). The main themes identified in synthesizing these ten articles were (1) population, (2) application of telehealth, (3) impact on reducing 30- day readmission, and (4) role of a healthcare provider.

\section{Population}

The population identified for this study were patients with stroke who received follow up care after discharge. Two of the articles (Nouh, et al., 2017; Strowd, Wise, \& Umei, 2014) recognized that patients with stroke experience a higher rate of readmission and strongly recommended that organizations focus on developing interventions to reduce readmission, such as early post-discharge follow up. Four descriptive articles (Rosen, McCall, \& Primack, 2017; Drissen, et al., 2016; O'Connor, et al., 2016; Collier, et al., 2015) indicated the use of telehealth benefitted non-stroke patients in skilled nursing facilities, patients in palliative care, and patients with congestive heart failure, COPD, and diabetes. 


\section{Applicability of telehealth}

The applicability of telehealth was a response to the innovation in healthcare to assist with the management of the aging population, rising healthcare costs, limited resources in rural communities, and specialized services such as palliative care and stroke care (Collier, et al., 2016; Van den Berg, et al., 2016). Two studies (Drissen, et al., 2016; Collier, et al., 2015) reported improved patient outcomes after integration of telehealth to their care plan outside of the hospital setting, particularly among patients in nursing home facilities and those under palliative care management. Patients who received telehealth interventions showed improvements in quality of life, depression, and mobility (Linder, et al., 2015). Incorporating a mediated telehealth exercise alleviated fatigue among caregivers of patients with chronic illnesses (Van den Berg, et al., 2016; Shahrokhi, et al., 2018). Telestroke is a type of telehealth application used by a neurologist to remotely provide urgent assistance in diagnosing acute stroke (McSweeney, Pritt, Swearingen, \& Kimble, 2017). This immediate intervention is crucial to save time and can dramatically improve the outcome of a stroke patient. (Wider, 2018).

\section{0-day readmission}

Regarding reducing 30-day readmission, six studies (Bambhroliya, et al., 2018; Nouh, et al., 2017; Vahidy, et al., 2017; Van den Berg, et al., 2016; Linder, et al., 2015; Strowd, Wise, \& Umei, 2014) analyzed telehealth impact on preventing hospitalization or decreasing 30-day readmission for stroke patients. Van den Berg, et al (2016) reported fewer readmissions among stroke patients over 12 months with tele-rehabilitation support at home. The need to provide an intervention to reduce readmission was based on other studies that determined an overall $14 \%$ readmission rate among patients with stroke resulting in close to 600-million-dollar cost to CMS (Gai \& Pachamanova, 2019). 


\section{Role of healthcare providers}

Health care providers, such as NPs, proved instrumental in implementing telehealth and were an integral part of bridging gaps in health care delivery (Henderson, et al., 2014). Two of the studies (Linder, et al, 2015; Collier, et al, 2015) utilized NPs in implementing telehealth for their patients and respective settings. Telehealth was viewed as a change to some nursing roles that traditionally defined their scope of work as providing direct patient care (Segar, et al., 2013). Telemedicine was not intended to replace direct patient care provided by healthcare professionals but augmented existing healthcare services (Segar, et al, 2013). Telehealth expanded provider's reach beyond their offices, allowing some to even work from home (Wider, 2018).

Evidence supported positive healthy outcomes for patients with stroke, particularly in reducing 30-day readmission rates (Kandola, et al, 2017). CMS (2020) updated an Evaluation and Management (E/M) service code 99441 for NPs and other health care professionals who performed telehealth phone visits to an established patient.

\section{Practice Recommendations}

The practice recommendations were based on a rigorous review of the literature from the evidence search strategy performed. The most important finding was that telehealth positively impacted patient outcomes, increased access, and simplified connectivity to the healthcare provider. The effectiveness of telehealth was based on findings consisting of self-reports based on focus groups, interviews, and surveys (Driessen, et al., 2016).

Telehealth also proved effective in redefining how services were rendered and improved the timeliness of appropriate care (Rosen, McCall, \& Primack, 2017). Six of the studies indicated reduction in 30-day hospital admissions with the use of telehealth as a component in the transition of care (O'Connor, et al., 2016). Efforts to provide education regarding telehealth lead 
to clarity, acceptance, and early adaption to meet the rapidly changing healthcare delivery system (Segar, et al., 2013). Based on consistent findings in support of patient-oriented use of telehealth, the strength recommendation was considered at level 1 on the Strength of Recommendation Taxonomy (Ebell, et al., 2004). A logical intervention for the PICOT question was based on a summary statement drawn after considering all data in this synthesis and all other articles cited (see Figure 2).

Figure 2: Practice Recommendation

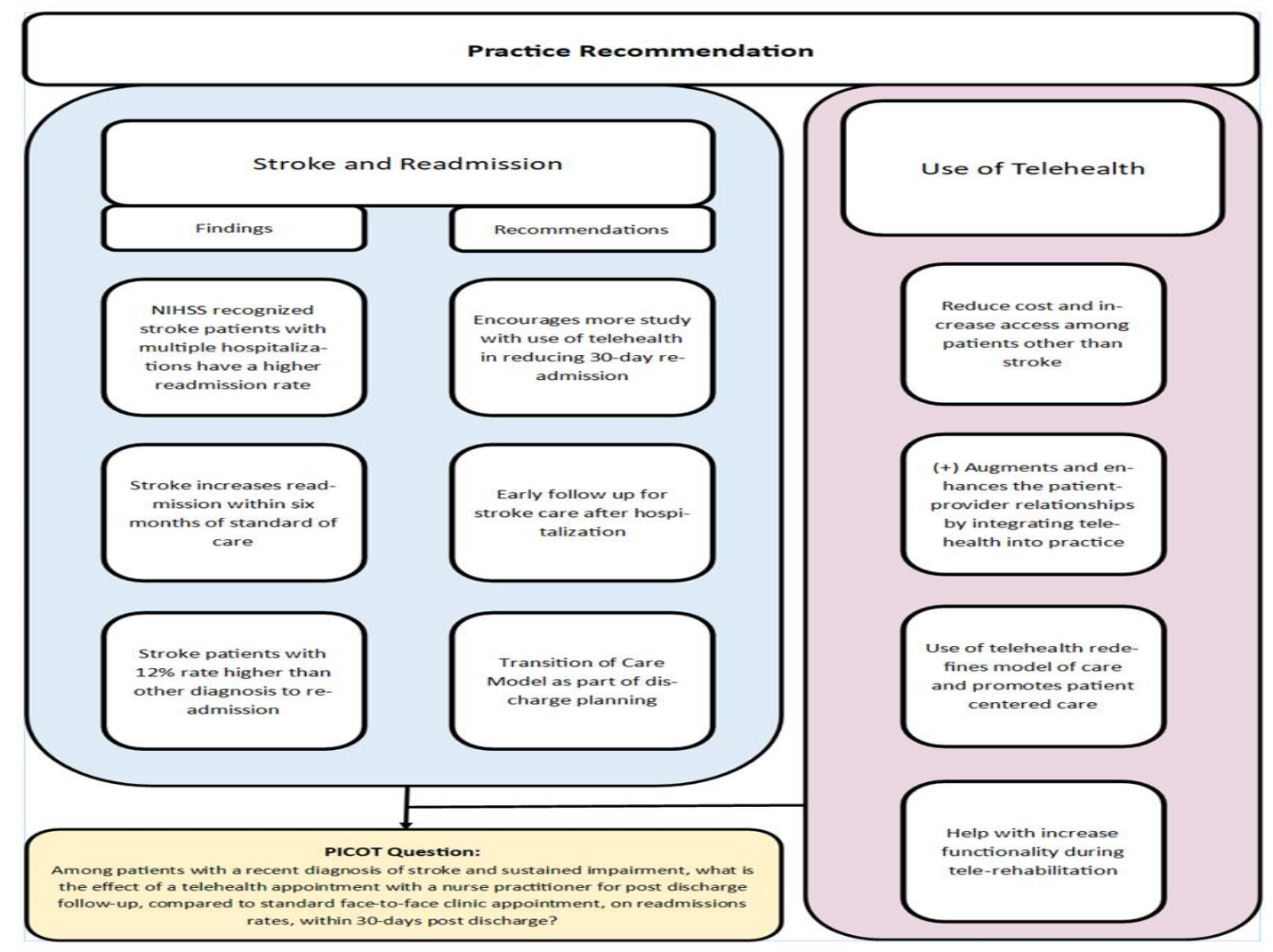

\section{Project Setting}

Gathering a detailed assessment from the organization to determine the need for the intervention was an important contextual element. As part of the complex structure of a local Department of Health Services, the agency provided care to patients who were residents of Los Angeles. The organization has a service excellence in stroke management caring for over 2,000 
patients with stroke aged 45 to 80 years old, including all genders from various ethnic backgrounds followed in its primary care clinics. Many of these patients were admitted from other hospitals for stroke rehabilitation due to deficits with mobility, speech, or cognition. Once discharged, they were followed in the outpatient stroke clinic.

\section{Mission and Vision}

The agency holds a unique position in the local health system by offering comprehensive rehabilitation needs and a robust outpatient clinic provides primary care service to this population with rehabilitation needs. The mission and vision are to provide high quality culturally sensitive patient centered care in a dynamic medical and rehabilitative environment. With the organization's priority to innovate and transform care delivery, telehealth provides an opportunity for the organization to increase patient access to care outside the hospital setting.

\section{Key Stakeholders}

The key stakeholders for the EBP change were comprised of the Chief Information Officer (CIO), Chief Nursing Office, Outpatient Medical Director, and Nurse Informaticist. Other stakeholders included the medical team in the inpatient stroke unit who set up telehealth phone clinic appointments prior to discharge. Stakeholders in the outpatient stroke unit were the patient care team for the stroke medical home team including medical providers, clerical support, and all levels of nursing. The most important stakeholders were recent stroke patients offered this service and in need of post discharge follow-up, experiencing impaired mobility from stroke, difficulty accessing transportation, or lacking familial support to get to a clinic appointment.

\section{Organizational Assessment and SWOT Analysis}

Three organizational assessment tools were used to determine organizational readiness for practice change and planning for the quality improvement project on telehealth clinic visits. 
The tools consisted of the IHI improvement Capability Self-Assessment tool (IHI, n.d.), the checklist that assessed organizational readiness (CARI) for evidence-informed practice (Barwickj, 2011), and the IHI Organizational and Informational Readiness checklist for integrated finance and safety (IHI, n.d.). In synthesizing these tools, the executive leadership was exemplary and ready to support implementation of telehealth in the outpatient clinic. The tools were consistent in identifying an area that needed attention where multidisciplinary collaboration and training was needed related to telehealth.

A SWOT analysis of the agency was performed to identify its strengths, weaknesses, opportunities, and threats (see Appendix B). Some of the strengths identified were strong leadership support, the agency's pursuit towards innovation, and the enthusiasm by the interdisciplinary team to use telehealth. Some of the weaknesses identified were telehealth use as new technology and new information, competing priorities, and staff resistance to change. Opportunities included utilizing existing implemented telehealth in the Department of Health Services, identifying the equipment to be used for telehealth, and interdisciplinary training and collaboration. The threats identified were patient's preference for face-to-face (F2F) appointments, their lack of access to a phone, regulatory requirements with telehealth, and impact to reimbursement.

\section{Project Overview}

The intended outcome of the project was to determine if a reduction in readmission rates below $14 \%$ occurred among patients who had a stroke within 30-days of discharge and within two months after implementing telehealth clinic appointments. The mission and vision of the project was to provide patient centered care in a dynamic rehabilitation environment. This aligned with a strategic priority of the agency and its mission and vision to provide restoration of 
health and hope with a focus on delivering patient and family-centered care. It was also reflected in the strategic goal to provide the right care at the right time and the right place (Rancho, n.d.). The short-term goal of the project was to implement the new workflow for telehealth phone visits and maintain consistency with using the protocol. The long-term goal was to expand application of telehealth by reducing the amount of readmission among patients with strokes.

\section{Unintended Risk and Consequences}

The project's unintended risks and consequences revolved around technology with connectivity issues and patient confidentiality. Mitigating these risks involved key stakeholders regarding devices and the implementation of a downtime procedure when delays in connectivity occurred. Regular checks of the equipment were performed to establish functionality during telehealth visits. The team members completed the Health Insurance Portability and Accountability Act (HIPAA) training and involved the CIO to mitigate risks on patients confidentially and breach of information. Telehealth policies were developed to capture patient's consent for telehealth. Other unintended consequences or risks associated with the project was resistance to integrating telehealth into standard practice, limitation of office space and furniture, patient's preference for standard-of-care with clinic appointments, and constraints imposed by organizational policy and other regulatory standards on telehealth. An ongoing risk assessment for the telehealth project was conducted to raise awareness for potential risks and consequences.

\section{Project Plan (Method)}

The planned project of implementing a telehealth appointment to follow-up stroke patients post-discharge was a systematic project to improve the current process on how care was delivered to the target population (Nelson \& Staggers, 2017). In support of the PICOT question, the project planned to compare patients who received telehealth phone visits to those patients 
who received standard face-to-face discharge follow up appointments and determine the impact on 30-day readmission rate during the study period. The goal was to reduce readmission rates to less than $14 \%$ by developing a process to implement telehealth phone visit. A process was developed on how to implement a telehealth phone visit, identified tools for patient recruitment, trained and educated the patient care team, including NPs, and evaluated the outcome. Early collaboration with the facility informatics team confirmed capabilities to provide telehealth services. The current process was refined, which included developing a specific electronic progress note for phone visits referred to as "Outpatient Phone Visit Note" for consistency of documentation. A flyer was distributed to patient care team as an invitation to convey the EBP change project. Attendance and completion of training by staff was tracked through a sign-in record (see Appendix C). The primary audiences selected for the training and orientation were given an in-service utilizing a power point presentation by the project manager regarding background of the project change proposal and implementation of telehealth phone visit within the organization (see Appendix D). The objectives of the presentation were to introduce the concept of telehealth phone visits, discuss its implication to nursing practice, identify the chosen population, and address new workflow on setting up an appointment and documenting a telehealth phone visit using a specific phone visit note type. The importance of implementing an EBP change with telehealth phone visit promoting access to care and mitigating potential 30-day readmission was stressed. The project manager also supplemented the participant's learning with a handout on how to conduct a telehealth phone visit and showed step-by-step where to find information in the EHR (see Appendix E). The job aid provided clarity to staff regarding their roles as a care team throughout the phone visit. A template for a phone visit progress note was developed to capture key elements to document including how to designate an evaluation and 
management $(\mathrm{E} / \mathrm{M})$ code that reflected clinical services provided to the patient and the duration of the phone visit encounter. The NP was trained to perform telehealth phone visits including the importance of accuracy in electronic documentation using the new "Outpatient phone visit note type" (see Appendix F).

\section{Iowa Model for Evidence-based Practice}

With the implementation of telehealth phone visits with the NP, the Iowa Model was used successfully to implement a practice change in the outpatient setting. Using the step-by-step approach of the Iowa model resulted in consolidation of leading evidence from research studies, clinician's competence, and patient's choice (Melnyk \& Fineout-Overholt, 2015).

The model began with identifying a problem-focused trigger, such as stroke readmission rate. The organization provides primary care services to 3,000 patients with a stroke. In comparison to the national readmission data, the local health care system has an $18 \%$ readmission rate for patients with stroke (Rancho, n.d.).

The second step was to acknowledge if this was a priority for the organization. Based on data of the local Department Health Services on stroke readmission rate, the facility found an opportunity to reduce the current readmission rate. Both leadership and key stakeholders identified the impact of a practice change, such as providing telehealth phone visits to mitigate this problem. Telehealth phone visits were rendered to patients as a discharge follow-up strategy that impacted reduction of hospital readmission among this population. Using telehealth phone visits for follow-up care helped improve services to patients, improved health care outcomes, and increased patient satisfaction (U.S. Department of Health and Human Services [HHS], 2018).

The third step was to form a group of key members for the project who assisted with the development, assessment, and implementation of the practice change. The project manager 
formed an outpatient care team from the Stroke Medical Home clinic comprised of a NP, RN, certified medical assistant (CMA), clerk, nurse informaticist, appointment schedulers, and representative from Information Technology (IT). The inpatient stroke unit patient care team introduced the telehealth phone visits and set up the telehealth phone appointment prior to discharge.

The fourth step was gathering relevant literature and research studies that helped formulate the PICOT question and strongly supported the proposed project change in delivering health care services. Critique of quantitative and qualitative studies, as the Iowa model suggests, revealed research supportive of improved patient outcomes after integration of telehealth to their medical care reporting reduction or avoidance of hospital readmissions (Van den Berg, et al., 2016; Driessen, et al., 2016; Linder et al., 2015). Additional studies supported the use of NPs in implementing telehealth for their patients (Linder, et al, 2015; Collier, et al., 2015).

The fifth step was a pilot implementation of the new telehealth phone visit protocol. As part of discharge planning from the inpatient unit, the patient was offered a telehealth phone visit with the NP within two weeks of being discharged from the hospital instead of the standard practice of a face-to-face clinic appointment. The project team provided training and orientation on the change project and implementation of telehealth using the guideline on how to conduct a phone visit (see Appendix G). Patients were informed a telehealth phone visit was available using a patient information sheet provided to them (see Appendix H). A copy of this signed information sheet was placed in the patient's health record. Appointment reminder phone calls proved effective in reducing no-show rates in the outpatient care setting (Shah, et al., 2016). The CMA called the patient two days prior to the clinic appointment. The NP was allotted 40 minutes to complete a telehealth phone visit encounter with the patient. 
The last step was to evaluate the impact of the practice change on stroke readmission rates. Data was monitored at 7 days, 30 days, and 60 days to determine 30-days post-discharge readmission rate among patients who received telehealth phone visit. A review of participants at 30 days to meet the 60-day timeframe for implementation was conducted. Information on patient outcomes and patient experiences were presented during monthly management meetings. A project timeline was provided (see Appendix I). By performing a chart review and generating a report from the facility's repository on admissions associated ICD-10 for stroke, readmission rates were determined among this target population. Two days after the phone visit appointment, the CMA contacted the patient by phone and completed a 12-question survey on the patient's experience with telehealth.

\section{Kotter's Model of change}

Applying Kotter's model of change aligned with the organization's process in providing clarification to potential misunderstandings that created resistance to change. There are three key components for Kotter's model of change: (1) initiate or create the climate for change, (2) implement or engage and enable the organization, and (3) institute or implement and sustain change (Kotter, 1995). Under the first component, the organization embraced telehealth as a growing concept, the project champions were identified, literature review was performed, and a project proposal was developed pertaining to changing face-to-face appointments to telehealth. Under the second component, telehealth was offered to patients with a recent stroke. Information Technology (IT) support prepared clinic appointment schedules and developed electronic health records. The project team set up launch dates and began staff training. One key metric for success was the reduction of 30-day readmission rates. Under the third component, data was reported using a dashboard and monthly reporting to the management team was 
scheduled highlighting the impact on patient outcomes satisfaction. The integration of practice change began in orientation and training with the core patient care team selected for the project. By spreading the word regarding telehealth, other services benefitted from this modality in managing their patients. Patients with stroke were scheduled a telehealth phone visit with the NP two weeks after discharge. The discharge nurse educated the patients regarding discharge follow up through telehealth in the outpatient setting.

\section{Interprofessional Team Collaboration}

The team members involved in the project implementation were the appointment schedulers, the RNs, the NPs, and the CMAs. The stakeholders for the EBP change were the patient care team in the inpatient stroke unit because they set up phone telehealth clinic appointments prior to discharge. In the outpatient setting, the stakeholders were the patient care team for the stroke medical home team.

\section{Project Budget}

A budget outlined an estimated total cost of the project and guided the care team in controlling cost (Neil \& Swig, 2017). In studying the budget related to the project, there were projected direct and indirect costs involving personnel salaries and benefits, training costs, equipment and supplies, and office space allocated for telehealth. The budget was minimal as the costs to the current infrastructure to support telehealth, such as computers, phones, and office space did not change. There was no additional staffing needed for this study. However, it was valuable to be keen on potential incurred costs to sustain the project, such as budgeting towards IT support and additional computer stations (see Table 1). 


\section{Table 1: Forecasted Project Budget}

\begin{tabular}{|c|c|c|}
\hline EXPENSES & & REVENUE PREDICTIONS \\
\hline Direct & & Billing \\
\hline $\begin{array}{l}\text { Existing Salary and } \\
\text { Benefits }\end{array}$ & $\$ 260,000$ & $\begin{array}{l}\text { Medicare } \\
\text { Medicaid } \\
\text { Own Insurance } \\
---- \text { Self-Pay }\end{array}$ \\
\hline RN Informatics & $\$ 60.00 /$ hourly rate & \\
\hline Supplies & & Grants \\
\hline $\begin{array}{l}\text { Office supplies (paper, } \\
\text { printer ink) }\end{array}$ & $\$ 200.00$ & Institutional budget support \\
\hline Statistician & $\$ 125.00 /$ hour & \\
\hline Computer desktop & $\$ 1,000.00$ & \\
\hline Telecommunication & $\$ 2,000.00$ & \\
\hline Training & $\$ 50.00 /$ session & \\
\hline Marketing & $\$ 100.00$ & \\
\hline \multicolumn{3}{|l|}{ Indirect } \\
\hline Overhead & pending & \\
\hline Total Expenses & $\$ 263,535$ & Total Revenue \\
\hline Net Bal & & \\
\hline
\end{tabular}

\section{Barriers}

There were a few identified barriers to success. The first was the uncertainty with the payment model or reimbursement for telehealth services. There was a lack of IT support and connectivity infrastructure. A barrier with patient's deficit in knowledge and awareness of telehealth impacted their engagement and willingness to participate with telehealth. To promote telehealth, the agency considered incentivizing enrollment by providing transportation for the next F2F appointment when necessary. Despite these barriers, the project was supported by key stakeholders, who worked collaboratively to ensure that minimal to no barriers for the implementation of the project arose. Administrative support was received from leadership in completing policy and procedural guidelines, identifying nursing support and training, securing office space for telehealth, and identifying NPs. The nurse informaticist performed data 
gathering and collection, worked with the project manager on data reporting, and coordinated the nursing care team for follow up on the use and adherence to protocols.

\section{Role of the DNP Student}

The DNP student performed the role of project manager providing oversight of the fruition of the EBP change proposal. The responsibilities included developing the PICOT question and performing a comprehensive literature review regarding use of telehealth in reducing 30-day readmission rate. The DNP student submitted the project proposal, coordinated meetings with the stakeholders, educated the staff, and established new workflows and processes to implement a successful phone visit. The DNP student developed a template for a phone visit notes for documentation in the EHR. In addition, the student participated in data collection and analysis. By utilizing the DNP's current role in the agency, she worked closely with identified key stakeholders regarding the practice change proposal. The project manager participated in evaluating the agency's readmission rate as part of the complex health care department in Los Angeles County. The DNP student communicated with leadership and key stakeholders regarding patient outcome findings from the EBP project and improved current processes in rendering care to stroke patients upon discharge.

\section{Results}

The USAHS Evidence Based Review Council and the facility’s Evidence-based Practice Council (EBPC) approved implementation of this project. Program evaluation was performed, and results were based on data collected to measure the effectiveness of the telehealth phone visit in reducing 30-day readmission rates among stroke patients. Patients, 18 years of age or older with a recent diagnosis of stroke of less than six months being discharged from a local county hospital, were eligible for a telehealth phone visit with a NP. Admissions and discharges were 
tracked with the Department of Health Services' discharge database based on admission with an associated diagnosis of stroke. The data collected on population included age, gender, comorbidities, and stroke diagnosis. Event data included discharge date, telehealth appointment date, and completion of telehealth visit. Outcome data was based on days since previous admission.

Data was collected from the patient's EHR and discharge databases at seven and 30 days for all participants to capture readmission rates. Evaluation tools captured nominal and numerical data and included analysis on process and outcome measures (see Appendix J). Data was collected and stored on SharePoint and an Excel sheet secured by a password login created by the DNP student. Integrity of the data collection process was ensured by using securely accessed EHRs, chart review for a completed telehealth visit using an audit tool and following standardized ICD-10 codes for identifying admissions with stroke-related diagnosis (see Appendix K). All patient care team members were familiar with the workflow and the inclusion and exclusion criteria and ongoing surveillance of data collection minimized missing data. Patient identifying information was removed from the data collection to follow HIPAA protocols. An unpaired t-test was used to report percentages of the variables to show differences among discharged patients who received a telehealth or in-person appointment. To assess patient experience, a 12-question telehealth survey was developed guided by evidence-based search and completed by the patients (see Appendix L).

Data collection occurred in the project implementation period of October 13, 2020 to November 13, 2020. During the reporting period, the stroke unit discharged a total of 46 patients. All were offered a telehealth phone visit as their follow-up appointment. Only 37 patients consented to use telehealth and were scheduled appointments. This translated to $80 \%$ of all total 
stroke discharges consented to participate in a telehealth appointment but only 32 patients completed a phone visit.

Participants of the study included adult patients discharged from the hospital with a diagnosis of stroke. The demographics of the participants are described in Table 2.

Table 2: Characteristics of Patients who Received Telehealth

\begin{tabular}{lcc}
\hline Number of Patients Completed & $n=32$ & $\%$ \\
\hline Average Age & 55 & \\
Age: & & $13 \%$ \\
$30-39$ & 4 & $16 \%$ \\
$40-49$ & 5 & $25 \%$ \\
$50-59$ & 8 & $46 \%$ \\
$>60$ & 15 & $40 \%$ \\
Female Gender & 13 & $66 \%$ \\
With medical insurance & 21 & $100 \%$ \\
With co-morbidities 2+ & 32 & $6.25 \%$ \\
Number of Readmission & 2 & \\
\hline
\end{tabular}

Out of 32 participants, two readmissions within 30 days from discharge occurred (see Table 3). One patient experienced urinary retention and the other abdominal pain. The national average for 30-day readmission among stroke patients is $14 \%$ (Centers for Disease Control and Prevention [CDC], 2019). For this project, the agency internally identified any percentage below the national benchmark as the project threshold for the 30-day readmission rate. This change project showed a $6.25 \%$ readmission rate within 30-days from discharge.

Table 3: Frequency Table for Nominal Variables

\begin{tabular}{lrr}
\hline Variable & $n$ & $\%$ \\
\hline X30 day readmission & & \\
Yes & 2 & 6.25 \\
No & 30 & 93.75 \\
Missing & 0 & 0.00 \\
\end{tabular}

Five patients did not show up for their appointment. An improved broken appointment rate at $13.5 \%$ for this study, compared to the $20 \%$ average broken appointment rate for this group 
at baseline, was found. Regulatory requirements state post-discharge follow up should be rendered within 10-14 days, and this project found that $27(87 \%)$ of all participants were seen within 10 days post-discharge. The results also showed that $23(72 \%)$ of all participants completed their telehealth appointment within the 40-minute phone visit time slot. This finding was consistent with utilizing the 40-minute allotted time for each telehealth appointment for an efficient F2F visit.

The average F2F clinic visit follow-up for patients after their initial post-discharge appointment occurred between 8 to 12 weeks later and found that stroke patients were seen for F2F appointments after participating in telehealth appointments an average of 9 weeks after their initial telehealth phone visit (see Table 4). This is comparable to the length of time when a patient would be routinely followed-up. All identified project team members were educated on the workflow on enrolling patients prior to discharge with telehealth phone visit appointments.

\section{Table 4: Timeliness and Duration of Visits}

\begin{tabular}{|l|l|}
\hline Number of Patients Seen for at least 40 minutes & 23 \\
\hline Number of Patients seen within 10-14 days & 28 \\
\hline Timeliness of phone visit (days) & $9.19(+/-3.63)$ \\
\hline Duration of Telehealth Visit in 40 minutes (minutes) & $45.69(+/-18.05)$ \\
\hline \# of days F2F visit scheduled after telehealth (days) & $52.90(+/-11.63)$ \\
\hline
\end{tabular}

The average cost of hospital admission is $\$ 23,000.00$ and this project noted a $6.25 \%$ readmission rate compared to the national average of $14 \%$. Based on the 32 participants, $14 \%$ (five patients) accounted for a total cost of $\$ 115,000$ toward hospital admission. This project noted a $6.25 \%$ readmission rate with two patients at a cost of $\$ 46,000$. Based on the data presented, there was a reduction of $7.75 \%$ readmission rate (3.5 patients) with potential cost savings of $\$ 69,000$. 
Only 21 of the 32 patients (66\% of participants) had billable payer sources, such as feefor-service, Medicare, or full scope medical insurance to pay for healthcare and other ancillary services covered by insurance, such as medical transportation. For the facility, participants with medical insurance were billed for telehealth services, impacting revenue.

Stroke patients are seen on an average of three times annually. Each visit costs $\$ 20.00$ for general transportation to a clinic appointment. Because these patients participated by phone, the potential cost-saving toward transportation was $\$ 60.00$ annually to the patient. This is particularly meaningful for the 11 participants (34\%) without any payer source.

In using descriptive analysis, provider and patient self-report were included on the use of telehealth. Based on the feedback received from the NPs during team meetings, the provider expressed satisfaction with their experiences using telehealth compared to F2F appointments. The provider noted positive interactions with patients due to convenience, ease of use, increased access to care, and embraced their roles with transforming how care was delivered to patients.

Patients received a patient experience survey two to three days after their telehealth phone visit. Out of the 32 participants, only 25 patients responded, making the response rate $78 \%$. Nearly $84 \%$ of the responders reported they agreed (value of 3 ) or strongly agreed (value of 4) with a positive experience using telehealth. Patients' direct quotes written on surveys were a mixture of both positive, negative, or neutral comments based on their experiences during the telehealth visits (see Table 5). 
Table 5: Subjective Comments about Telehealth from Stroke Patients

\begin{tabular}{|c|c|}
\hline Positive Comments & Negative/Neutral Comments \\
\hline $\begin{array}{l}\text { - } \quad \text { Everything was good } \\
\text { - } \text { They did a good job } \\
\text { - } \text { Completely satisfied } \\
\text { provided at this facility } \\
\text { - I see the possibilities of telehealth due to } \\
\text { convenience to patients } \\
\text { - Saves time, it's a good thing } \\
\text { - I see the possibilities. It was helpful } \\
\text { during this time/pandemic } \\
\text { - Satisfied, don't have any } \\
\text { recommendations. }\end{array}$ & $\begin{array}{l}\text { - } \text { prefer to be in-person in the future } \\
\text { appointment } \\
\text { - In-person is more personable } \\
\text { Did not return call. Asked to monitor } \\
\text { blood pressure for medication. Still } \\
\text { waiting for a call } \\
\text { - Speaking, expecting a call \& doesn't get a } \\
\text { call back } \\
\text { OK for MD visits and consultation. } \\
\text { Prefer to go in-person for therapy visits } \\
\text { I do not like telehealth, prefer personal } \\
\text { visits. Want to go back to normal. Need } \\
\text { MRI can't do by phone or video }\end{array}$ \\
\hline
\end{tabular}

Based on the reported findings from the EBP change project, there was clinical significance with telehealth as an option for stroke patients who received their post-discharge follow up care. The EPB project change met the goal based on data presented, which suggests telehealth was an effective intervention for reducing 30-day readmission rate among patients with stroke. Other data results, such as the patient satisfaction survey, provider feedback, timely access to phone visit appointments, and length of phone visits, showed that both quality of care and efficiency were not compromised by the telehealth phone visits.

\section{Impact}

The implementation of telehealth phone visits by NPs reduced readmission rates among patients with stroke. Adoption of this practice has positively impacted healthcare by providing an alternative for patients on how they want to receive follow up care after hospitalization. This project resulted in access to care within ten days of discharge, reduced broken appointment rates, and lowered readmission rates. The efficiency of a telehealth phone visit is comparable to a F2F appointment. Based on self-reports by the participants, patients responded positively to the 
convenience of telehealth and displayed a preference to receiving telehealth phone visits over F2F visits for their post-discharge follow up.

The successful completion of the EBP practice change provided guidance on successful execution of telehealth phone visits, which can easily be replicated by utilizing developed workflows, processes, training modules, and evaluation tools. To further improve the practice problem, data collection period was extended to permit a larger sample size and expand the participants to non-stroke patients. The program continued tracking efficacy through monthly data reporting and analysis of patient survey results. In addition, stakeholder engagement and staff training were crucial strategies for sustainability.

The impact of this project is limited by the dependence on access to technology. If the patient did not have access to a computer, a smart phone or other devices that would allow for telehealth visit, then the patient had to opt for a F2F appointment. If this project is to be replicated, overall time spent during an F2F clinic visit (from check-in to discharge) versus a telehealth clinic time with the NP should be reviewed. The potential time saved can be converted into additional appointment slots for the provider, as this information is lacking from the EBP project change regarding the increase in the number of patients who can be seen through telehealth visits.

\section{Plans for Dissemination}

The result of this project will be communicated using a PowerPoint presentation within the organization at a one-hour town hall meeting in a reserved auditorium. A flyer and invitation will be emailed to relevant participants and a poster displayed in the outpatient clinic for staff to view will encourage discussion and interest. Allowing the NPs who utilized and incorporated telehealth into their clinical practice to share their experience at the presentation and transfer 
knowledge encourages others to transform their own processes in their respective organizations promoting sustainability of the project change.

Regional dissemination of the project results may benefit adjacent counties who render specialty and rehabilitation care. The five other county facilities within the vast health care department will receive the project results through the monthly DHS meeting attended by interprofessional team members.

The facility supports design and printing of posters for various presentations. Since the focus is on the outpatient care setting and increasing integration of telehealth into clinical practice, the ideal presentation would occur at the American Association of Ambulatory Care Nursing (AAACN) annual conference. Presenting the project to the American Academy of Nurse Practitioners (AANP) would share success among NPs, empowering them to begin conversation about this modality within their own practices.

Submitting the project to a publishing repository, such as SOAR@USA or ProQuest, offers visibility to the public about the EBP change of using telehealth to enhance patient care delivery. The Journal of Nurse Practitioner, or American Journal of Nursing would provide relevant avenues for publication. The manuscript will be reviewed by the institutions' EBRC for feedback to produce high quality work. Requesting a peer review within the organization allows a collaborative presence in the review.

\section{Conclusion}

Stroke patients experience a national readmission rate of $14 \%$ within the first month of diagnosis (CHHS.gov). With the development of HRRP, organizations seek strategies to reduce 30-day readmission to improve patient outcomes and minimize impact to reimbursement rates (CMS, 2019). The project utilized an Iowa Model for EBP change and Kotter's model of change 
to discuss proposals aimed at decreasing 30-day readmission rates for stroke patients through telehealth phone visits. The usefulness of telehealth, sustainability, and potential for widespread implementation were based on multiple key findings from the EBP change project on readmission rate, information gathered from the evaluation tool, and on the willingness of the patient care team to integrate telehealth as a key component of health care delivery. The change project presented an opportunity to reduce readmission rates among stroke patients and rendered a framework to determine if telehealth visits will reduce 30 -day readmission rate among stroke patients. 


\section{References}

Agency for Healthcare Research and Quality (2020). Primary care-based efforts to reduce potentially preventable readmissions. https://www.ahrq.gov

Bambhroliya, A., Donnelyu, J., Tomas, E., Tyson,J., Miller,C., MucCullough, L., Saitz, S, Vahidy, F. (2018). Estimates and temporal trends for US nationwide 30day hospital readmission among patients with ischemic and hemorrhagic stroke. JAMA, 1(4). http://doi.org.10:1001/jamanetrowrkopem.2018.1190

Barwicjk, M.A. (2011). Checklist to assess organizational readiness (CARI) for EIP implementation. Retrieved from http://www.effectiveservices.org/downloads/Checklist_to_Assess_Organisational_Readin ess_for_Implementation.pdf.

Boehm, N., Muehlberg, H., \& Stube, J. (2015). Managing post stroke fatigue using telehealth: A case report. Journal of Occupational Therapy, 69(6), 1-7.

Brown, C. G. (2014). The Iowa model of evidence-based practice to promote quality care: An illustrated example in oncology nursing. Clinical Journal of Oncology Nursing, 18(2), 157-159. https://doi.org/10.1188/14.CJON.157-159

Carroll, K. (2018). Transforming the art of nursing: telehealth technologies. Nursing Science Quarterly, 31(3), 230-232. https://doi.org/10.1177/0894318418774930

CDC, Centers for Disease Control and Prevention (2015). International Classification of Diseases, (ICD-10-CM/PCS) Transition-Background. https://www.cdc.gov/nchs/icd/icd10cm_pcs_background.htm 
Center for Medicare and Medicaid Services (2020). Medicare telemedicine health care provider fact sheet (2020). https://www.cms.gov/newsroom/fact-sheets/medicare-telemedicinehealth-care-provider-fact-sheet

Centers for Disease Control and Prevention. (2019). Stroke facts. https://www.cdc.gov/stroke/facts.htm

Centers for Medicare \& Medicaid Services. (2019). https://www.cms.gov/

Collier, A., Morgan, D. D., Swetenham, K., To, T. H. M., Currow, D. C., \& Tieman, J. J. (2016). Implementation of a pilot telehealth programme in community palliative care: A qualitative study of clinicians’ perspectives. Palliative Medicine, 30(4), 409-417. https://doi-org.prx-usa.lirn.net/10.1177/0269216315600113

Doody, C.M. \& Doody, O. (2013). Introducing evidence into nursing practice: using the IOWA model. British Journal of Nursing, 20(11).

https://doi.org/10.12968/bjon.2011.20.11.661

Driessen, J., Bonhomme, A., Chang, W., Nace, D. A., Kavalieratos, D., Perera, S., \& Handler, S. M. (2016). Nursing home provider perceptions of telemedicine for reducing potentially avoidable hospitalizations. Journal of the American Medical Directors Association, 17, 519-524. https://doi.org/10.1016/j.jamda.2016.02.004.

Ebell, M.H, Siwek J, Weiss B.D, Woolf, S.H., Susman, J., Ewigman, B., \& Bowman (2004). Strength of recommendation taxonomy (SORT): a patient-centered approach to grading evidence in the medical literature. American Family Physician, 69(3),548-556. https://pubmed.ncbi.nlm.nih.gov/14971837/ 
Fischer, C., Lingsma, H. F., Marang-van de Mheen, P. J., Kringos, D. S., Klazinga, N. S., \& Steyerberg, E. W. (2014). Is the readmission rate a valid quality indicator? A review of the evidence. PloS one, 9(11). https://doi.org/10.1371/journal.pone.0112282

Gai, Y., Pachamanova, D. (2019). Impact of the Medicare hospital readmissions reduction program on vulnerable populations. BMC Health Services Research, 19(837). https://doi.org/10.1186/s12913-019-4645-5

Gorelick, P. (2019). The global burden of stroke: Persistent and disabling. The Lancet Neurology, 18(5), 417-418. DOI: https://doi.org/10.1016/S1474-4422(19)30030-4

Healthy People 2020. (2019). https://www.healthypeople.gov/

Henderson, K., Davis, T. C., Smith, M., \& King, M. (2014). Nurse practitioners in telehealth: bridging the gaps in healthcare delivery. Journal for Nurse Practitioners, 10(10), 845850. https://doi.org/10.1016/j.nurpra.2014.09.003

Hicks, S. A., \& Cimarolli, V. R. (2018). The effects of telehealth use for post-acute rehabilitation patient outcomes. Journal of Telemedicine \& Telecare, 24(3), 179-184. https://doiorg.prX-usa.lirn.net/10.1177/1357633X16686771

Hospital Readmissions Reduction Program (2020). Centers for Medicare and Medicaid Services. https://www.cms.gov/Medicare/Quality-Initiatives-Patient-Assessment$\underline{\text { Instruments/Value-Based-Programs/HRRP/Hospital-Readmission-Reduction-Program }}$

IHI (n.d.). IHI improvement capability self-assessment tool. Retrieved from http://app.ihi.org/FacultyDocuments/Events/Event-2354/Presentation-9119/Document7406/L2 Improvement Tool.pdf

Intellectus Statistics [Online computer software]. (2020). Intellectus Statistics. $\underline{\text { https://analyze.intellectusstatistics.com/ }}$ 
Johnson, B. H., Bonafede, M. M., \& Watson, C. (2016). Short- and longer-term health-care resource utilization and costs associated with acute ischemic stroke. Clinical Economics Outcome Research, 8, 53-61. https://doi.org/10.2147/CEOR.S95662

Joshi, M. S., Ransom, E. R., Nash, D. B. \& Ransom, S. B., eds. (2014). The healthcare quality book: Vision, strategy, and tools (3rd ed.). Chicago, IL: Health Administration Press.

Kandola, D. K., Banner, D., Araki, Y., Bates, J., Hadi, H., \& Lear, S. A. (2018). The participant recruitment outcomes (PRO) study: Exploring contemporary perspectives of telehealth trial non-participation through insights from patients, clinicians, study investigators, and study staff. Contemporary Clinical Trials Communications, 11, 75-82. https://doi.org/10.1016/j.conctc.2018.005

Kotter, J. (1995). Leading change: Why transformation efforts fail. Harvard Business Review, 73(2), 59-67. Retrieved from https://hbr.org/magazine

LADHS (n.d.) Los Angeles Department of Health Services. https://dhs.lacounty.gov

Linder, S., Rosenfeldt, A., Bay, C. Sahu, K., Wolf, S., and Alberts, J (2015). Improving quality of life and depression after stroke through telerehabilitation. American Journal of Occupational Therapy, 69(2), 1-11

McSweeney, S., Pritt, J. A., Swearingen, A., Kimble, C. A., \& Coustasse, A. (2017). Telestroke: Overcoming Barriers to Lifesaving Treatment in Rural Hospitals. Perspectives in Health Information Management, 1-18. Retrieved from http://prxusa.lirn.net/login?url=http://search.ebscohost.com/login.aspx?direct=true\&db=ccm\&AN $=124305212 \&$ site $=$ eds-live

Melnyk, B., \& Fineout-Overholt, E. (2015). Evidence-based Practice in Nursing \& Healthcare. A guide to Best Practice ( $3^{\text {rd }}$ ed). Philadelphia: Wolters Kluwer. 
Neil, B. \& Swig, B. (2017). Project management for the healthcare practices: Costs and timing. Practice Management, 32(4), 271-275.

Nelson, R. and Staggers, N. (2017). Health informatics, An Interprofessional approach, 2nd edition. St. Louis, MO: Elsevier

Nouh, A. M., McCormick, L., Modak, J., Fortunato, G., \& Staff, I. (2017). High mortality among 30-day readmission after stroke: Predictors and etiologies of readmission. Frontiers in Neurology, 8, 632. https://doi.org/10.3389/fneur.2017.00632

O’Connor, M., Asdornwised, U., Dempsey, M., Huffenberger, A., Jost, S., Norris, A. (2016). Using telehealth to reduce all cause 30-day hospital readmissions among heart failure patients receiving skilled home health services. Applied Clinical Informatics, 7, 238-247. http://dx.doi.org/10.4338/ACI-2015-11-SOA-0157.

Poston, K. (2018). Reducing readmissions in stroke patients: Recognizing those at risk and exploring evidence-based strategies. American Nurse Today, 13(12), 9-15.

PRISMA (n.d.). Preferred Reporting Items for Systematic Reviews and Meta-Analysis. Www.prisma-statement.org.

Rancho Los Amigos National Rehabilitation Center. (n.d). Los Angeles Department of Health Services- Rancho Los Amigos Home. http://dhs.lacountyg.gov/wps/portal/dhs/rancho

Reineck, C. (2007). Models of change. The Journal of Nursing Administration, 37(9), 388- 391. https://doi.org/10.1097/01.nna.0000285137.26624.f9

Rosen, D., McCall., \& Primack, B. (2017). Telehealth protocol to prevent readmission among high-risk patients with congestive heart failure. American Journal of Medicine, 6(11), 1326. 
Ross, S.Y.; Roberts, S., Taggart, H., Patronas, C. (2017). Stroke transitions of care. Medsurg Nursing, 26 (2), 119-123.

Segar, J., Rogers, A., Salisbury, C., \& Thomas, C. (2013). Roles and identities in transition: boundaries of work and inter-professional relationships at the interface between telehealth and primary care. Health \& Social Care in the Community, 21(6), 606-613. https://doi.org/10.1111/hsc.12047

Serper, M., \& Volk, M. L. (2018). Current and future applications of telemedicine to optimize the delivery of care in chronic liver disease. Clinical Gastroenterology and Hepatology: The Official Clinical Practice Journal of the American Gastroenterological Association, 16(2), 157-161. https://doi.org/10.1016/j.cgh.2017.10.004

Shah, S.J., Cronin, P., Hong, C.S. et al. (2016). Targeted reminder phone calls to patients at high risk of no-show for primary care appointment: A randomized trial. J GEN INTERN MED 31, 1460-1466. https://doi.org/10.1007/s11606-016-3813-0

Shahrokhi, A., Azimian, J., Amouzegar, A., \& Oveisi, S. (2018). Effect of telenursing on outcomes of provided care by caregivers of patients with head trauma after discharge. Journal of Trauma Nursing, 25(1), 21-25. https://doi-org.prxusa.lirn.net/10.1097/JTN.0000000000000338

Smith, D. (2007). Transforming the care delivery model in preparation for the clinical nurse leader. The Journal of Nursing Administration, 37(4), 157- 160. https://doi.org/10.1097.01.nn1.0000266844.00050.5e.

Strowd, R., Wise, S., \&Umei, N. (2014). Predictors of 30-day hospital readmission following ischemic and hemorrhagic stroke. American Journal of Medical Quality, 30(5), 441-446. 
Terman, S. W., Reeves, M. J., Skolarus, L. E., \& Burke, J. F. (2018). Association between early outpatient visits and readmissions after ischemic stroke. Circulation: Cardiovascular Quality and Outcomes, 11(4). https://doi.org/10.1161/CIRCOUTCOMES.117.004024

The GBD 2016 Lifetime Risk of Stroke Collaborators (2018). Global, Regional, and CountrySpecific Lifetime Risks of Stroke, 1990 and 2016 report. New England Journal of Medicine, 379:2429-2437. https://doi.org/10.1056/NEJMoa1804492

Vahidy, F., Donnelly, J., McCullough, L., Tyson, J., Miller, C., Boehme, A., Savitz, S. \& Allbright, K. (2017). Nationwide estimates of 30-Day readmission rates in patients with ischemic stroke. AHA Journals, 1386-1388. https://doi.org/10.1161/STROKEAHA.116.01608

Van den Berg, M., Crotty, M., Enwu Liu, Killington, M., Kwakkel, G., van Wegen, E., ... Kwakkel, G., Prof. (2016). Early supported discharge by caregiver-mediated exercises and e-Health support after stroke: A proof-of-concept trial. Stroke, 47(7), 1885-1892. https://doi-org.prx-usa.lirn.net/10.1161/STROKEAHA.116.013431

Wang, G., Zhang, Z., Ayala, C., Dunet, D., Fang, J., \& George, M. (2013). Costs of hospitalization for stroke patients aged 18-64 years in the United States. Journal Stroke Cerebrovascular Disease, 23(5), 861-8. https://doi.org/10.1016/j.jstrokecerebrovasdis.2013.07.017

Wider, J. (2018). Telehealth impacts ROI, patient safety. Health Management Technology, 39(2), 6.

World Stroke Organization (2016) Global stroke fact sheet. https://www.world$\underline{\text { stroke.org/assets/downloads/WSO_Global_Stroke_Fact_Sheet.pdf }}$ 


\section{Appendix A}

Summary of Primary Research Evidence

\begin{tabular}{|c|c|c|c|c|c|c|}
\hline Citation & $\begin{array}{c}\text { Design, } \\
\text { Level } \\
\text { Quality } \\
\text { Grade } \\
\end{array}$ & $\begin{array}{c}\text { Sample } \\
\text { Sample size }\end{array}$ & $\begin{array}{c}\text { Intervention } \\
\text { Comparison } \\
\text { (Definitions should } \\
\text { include any specific } \\
\text { research tools used } \\
\text { along with reliability } \& \\
\text { validity) }\end{array}$ & $\begin{array}{l}\text { Theoretical } \\
\text { Framework }\end{array}$ & Outcome Definition & $\begin{array}{c}\text { Usefulness } \\
\text { Results } \\
\text { Key Findings }\end{array}$ \\
\hline $\begin{array}{l}\text { Van den Berg, } \\
\text { M., Crotty, M., } \\
\text { Enwu Liu, } \\
\text { Killington, M., } \\
\text { Kwakkel, G., van } \\
\text { Wegen, E., ... } \\
\text { Kwakkel, G. } \\
\text { (2016). Early } \\
\text { supported } \\
\text { discharge by } \\
\text { caregiver- } \\
\text { mediated } \\
\text { exercises and e- } \\
\text { health support } \\
\text { after stroke: A } \\
\text { proof-of-concept } \\
\text { trial. Stroke, } \\
\text { 47(7), 1885- } \\
\text { 1892. https://doi- } \\
\text { org.prx- } \\
\text { usa.lirn.net/10.11 } \\
\text { 61/STROKEAHA } \\
.116 .013431\end{array}$ & $\begin{array}{l}\text { Research } \\
\text { Design: } \\
\text { Proof-of- } \\
\text { concept trial, } \\
\text { randomized } \\
\text { controlled. } \\
\text { LEVEL } 1 \\
\text { very high } \\
\text { quality } \\
\text { article }\end{array}$ & $\begin{array}{l}\text { Sample Size: } 63 \\
\text { hospitalized } \\
\text { stroke patients } \\
\text { with average } \\
\text { age of } 68 \text { years; } \\
64 \% \text { of } \\
\text { participants are } \\
\text { female. }\end{array}$ & $\begin{array}{l}\text { Research Tools Used: } \\
\text { Stroke Impact Scale } \\
\text { mobility domain and for } \\
\text { Data Analysis a descriptive } \\
\text { statistic was used to } \\
\text { examine the data; using } \\
\text { intention-to-treat principle; } \\
\text { intervention was tested } \\
\text { using linear mixed models } \\
\text { which are group, time, and } \\
\text { group x time and baseline } \\
\text { scores. }\end{array}$ & $\begin{array}{l}\text { Chronic } \\
\text { disease } \\
\text { Management }\end{array}$ & $\begin{array}{l}\text { An 8-week program of CME } \\
\text { and e-health support will have } \\
\text { improved mobility, reduce } \\
\text { hospital stay, and reduce burden } \\
\text { to caregivers. } \\
\text { CME supported by tele- } \\
\text { rehabilitation augments intensity } \\
\text { of practice, resulted in improved } \\
\text { ADL, reduces hospital days with } \\
\text { fewer readmissions post stroke } \\
\text { and reduced levels of caregiver } \\
\text { fatigue }\end{array}$ & $\begin{array}{l}\text { The findings from the study } \\
\text { justifies a larger randomized } \\
\text { controlled trial in a multicenter } \\
\text { to evaluate the effectiveness and } \\
\text { cost-effectiveness of the } \\
\text { intervention and indirect cost } \\
\text { savings from preventing } \\
\text { readmissions. } \\
\text { Recommends future studies in } \\
\text { other post-discharge settings } \\
\text { such as nursing homes and its } \\
\text { applicability of CME to patients } \\
\text { with brain injury. }\end{array}$ \\
\hline $\begin{array}{l}\text { Driessen, J., } \\
\text { Bonhomme, A., } \\
\text { Chang, W., Nace, } \\
\text { D. A., } \\
\text { Kavalieratos, D., } \\
\text { Perera, S., \& }\end{array}$ & $\begin{array}{l}\text { Research } \\
\text { Design: } \\
\text { Survey to be } \\
\text { completed by } \\
\text { attendees of } \\
\text { the } 2015\end{array}$ & $\begin{array}{l}\text { Sample Size: } 435 \\
\text { completed } \\
\text { surveys were } \\
\text { received from } 947 \\
\text { conference } \\
\text { attendees; they }\end{array}$ & $\begin{array}{l}\text { Research Tools Used are the } \\
\text { 4-point Likert scale ranging } \\
\text { from "extremely important" } \\
\text { to "not very important" with } \\
\text { lower number being most } \\
\text { important; the survey was }\end{array}$ & Undefined & $\begin{array}{l}\text { Telemedicine may reduce PAH } \\
\text { among nursing home residents. } \\
\text { More research in needed to } \\
\text { objectively study the impact } \\
\text { of successful telemedicine }\end{array}$ & $\begin{array}{l}\text { Strongest agreement among } \\
\text { responders with statement } \\
\text { "telemedicine may fill existing } \\
\text { service gap and "telemedicine } \\
\text { may improve timeliness of } \\
\text { appropriate resident cate". }\end{array}$ \\
\hline
\end{tabular}




\begin{tabular}{|c|c|c|c|c|c|c|}
\hline $\begin{array}{l}\text { Handler, S. M. } \\
\text { (2016). Original } \\
\text { study: nursing } \\
\text { home provider } \\
\text { perceptions of } \\
\text { telemedicine for } \\
\text { reducing } \\
\text { potentially } \\
\text { avoidable } \\
\text { hospitalizations. } \\
\text { Journal of the } \\
\text { American } \\
\text { Medical Directors } \\
\text { Association, 17, } \\
\text { 519-524. } \\
\text { doi:10.1016/j.jam } \\
\text { da.2016.02.004. }\end{array}$ & $\begin{array}{l}\text { AMDA } \\
\text { annual } \\
\text { conference. } \\
\text { LEVEL 1 } \\
\text { very high } \\
\text { quality } \\
\text { article }\end{array}$ & $\begin{array}{l}\text { are either a } \\
\text { physician or } \\
\text { Advanced } \\
\text { Practice } \\
\text { providers; } 55 \% \\
\text { are male. }\end{array}$ & $\begin{array}{l}\text { beta tested prior to use at the } \\
\text { conference. } \\
\text { Data Analysis: completed } \\
\text { survey were entered in } \\
\text { Microsoft ACCESS } \\
\text { database with dual entry of } \\
\text { all responses to ensure } \\
\text { accuracy; survey responses } \\
\text { were summarized based on } \\
\text { means, SD, frequencies, and } \\
\text { percentages. }\end{array}$ & & $\begin{array}{l}\text { implementation on patient, } \\
\text { providers, and economic } \\
\text { outcomes. }\end{array}$ & $\begin{array}{l}\text { Responders strongest } \\
\text { disagreements with statement } \\
\text { "telemedicine may reduce reside } \\
\text { care effectiveness" and that } \\
\text { "telemedicine may jeopardize } \\
\text { resident privacy". } \\
\text { Findings indicated confidence in } \\
\text { telehealth to fill existing gaps } \\
\text { and improve timeliness of care } \\
\text { among nursing home residents. }\end{array}$ \\
\hline $\begin{array}{l}\text { Collier, A., } \\
\text { Morgan, D. D., } \\
\text { Swetenham, K., } \\
\text { To, T. H. M., } \\
\text { Currow, D. C., \& } \\
\text { Tieman, J. J. } \\
\text { (2016). } \\
\text { Implementation } \\
\text { of a pilot } \\
\text { telehealth } \\
\text { program in } \\
\text { community } \\
\text { palliative care: A } \\
\text { qualitative study } \\
\text { of clinicians' } \\
\text { perspectives. } \\
\text { Palliative } \\
\text { Medicine, 30(4), } \\
\text { 409-417. doi: } \\
\text { 10.1177/0269216 } \\
\text { 315600113 }\end{array}$ & $\begin{array}{l}\text { Research } \\
\text { Design: } \\
\text { Focus groups } \\
\text { and semi- } \\
\text { structured } \\
\text { interviews } \\
\text { LEVEL } 2 \\
\text { high } \\
\text { quality } \\
\text { articles }\end{array}$ & $\begin{array}{l}\text { Sample Size: } 10 \\
\text { participants in a } \\
\text { metropolitan } \\
\text { palliative care in } \\
\text { Australia, such as } \\
\text { nurse practitioner, } \\
\text { community nurse, } \\
\text { or a liaison nurse } \\
\text { providing care } \\
\text { using a telehealth } \\
\text { program; } 2 \\
\text { interviews from } \\
\text { senior managers. }\end{array}$ & $\begin{array}{l}\text { Research Tools Used: } \\
\text { Telehealth self-monitoring } \\
\text { tool using PCOC, a } \\
\text { standardized clinical } \\
\text { assessment tool to measure } \\
\text { and benchmark patient } \\
\text { outcomes; Data analysis is } \\
\text { from focus groups; } \\
\text { interviews were audio } \\
\text { recorded and transcribed } \\
\text { verbatim using a grounded } \\
\text { theory approach to analyze } \\
\text { data. Coding categories } \\
\text { were developed and } \\
\text { interrogated by the authors } \\
\text { in relation to overall project } \\
\text { processes and findings; } \\
\text { ethics clearance was granted } \\
\text { by the Adeline Clinical } \\
\text { Human Research Ethics } \\
\text { Committee. }\end{array}$ & $\begin{array}{l}\text { Chronic Care } \\
\text { model }\end{array}$ & $\begin{array}{l}\text { Providers considered telehealth } \\
\text { to augment current service to } \\
\text { complement and not to replace } \\
\text { face-to-face clinical encounter } \\
\text { with patients; there was a } \\
\text { challenge to the team once the } \\
\text { telehealth technology was } \\
\text { introduced; the potential change } \\
\text { to the dynamic between patient, } \\
\text { families and clinicians may have } \\
\text { altered. } \\
\text { Aim is to explore clinician's } \\
\text { perspectives and experiences } \\
\text { from the utilization of a pilot } \\
\text { telehealth model and its } \\
\text { integration into a specialist } \\
\text { community providing palliative } \\
\text { care }\end{array}$ & $\begin{array}{l}\text { Revealed four themes in the } \\
\text { findings: Redefining model for } \\
\text { care instead of business as usual, } \\
\text { positive clinical benefits of } \\
\text { telehealth, person-centered } \\
\text { symptom management, and } \\
\text { issues with telehealth } \\
\text { technology. Needs reliable } \\
\text { Information Technology } \\
\text { infrastructure and technical } \\
\text { support; needs to involve } \\
\text { clinicians and managers to work } \\
\text { with technical staff in the design } \\
\text { and introduction of the telehealth } \\
\text { model }\end{array}$ \\
\hline
\end{tabular}




\begin{tabular}{|c|c|c|c|c|c|c|}
\hline $\begin{array}{l}\text { Linder, S. M., } \\
\text { Rosenfeldt, A. B., } \\
\text { Bay, R. C., Sahu, } \\
\text { K., Wolf, S. L., \& } \\
\text { Alberts, J. L. } \\
\text { (2015). } \\
\text { Improving quality } \\
\text { of life and } \\
\text { depression after } \\
\text { stroke through } \\
\text { tele rehabilitation. } \\
\text { American Journal } \\
\text { of Occupational } \\
\text { Therapy, 69(2), } \\
\text { 1-11. } \\
\text { doi:10.5014/ajot.2 } \\
015.014498\end{array}$ & $\begin{array}{l}\text { Research } \\
\text { Design is a } \\
\text { prospective, } \\
\text { multi-site } \\
\text { randomized } \\
\text { controlled } \\
\text { clinical trial } \\
\text { using two } \\
\text { groups: (1) } \\
\text { robot } \\
\text { assisted } \\
\text { therapy, (2) } \\
\text { home } \\
\text { exercise } \\
\text { program in } \\
\text { an 8-week } \\
\text { intervention. } \\
\text { Research } \\
\text { Tools Used: } \\
\text { SIS and } \\
\text { CED-S } \\
\text { domain; } \\
\text { Fugl-Meyer } \\
\text { assessment } \\
\text { tool for UE } \\
\text { functional } \\
\text { evaluation. } \\
\text { LEVEL } 2 \\
\text { high } \\
\text { quality } \\
\text { article }\end{array}$ & $\begin{array}{l}\text { Sample Size: } 99 \\
\text { participants from } \\
\text { Ohio and Georgia } \\
\text { with unilateral } \\
\text { stroke less than } 6 \\
\text { months }\end{array}$ & $\begin{array}{l}\text { Data Analysis: a customized } \\
\text { Microsoft access database } \\
\text { was used to double enter } \\
\text { data. Cronbach's alpha was } \\
\text { used to estimate internal } \\
\text { consistency of scales. } \\
\text { Independent-sample t-test } \\
\text { was used to compare two } \\
\text { groups based on } \\
\text { demographics and clinical } \\
\text { characteristics for } \\
\text { continuous variables. A chi- } \\
\text { square or Fisher's exact } \\
\text { tests was used for } \\
\text { categorical variables. } \\
\text { The data analysis involved } \\
\text { all participants' data } \\
\text { whether they are in: (1) a } \\
\text { home exercise program or } \\
\text { (2) robot-assisted therapy }+ \\
\text { home exercise program and } \\
\text { participated in an 8-week } \\
\text { home intervention. Data } \\
\text { analyses were completed } \\
\text { using IBM SPSS Statistics } \\
\text { version } 22 \text {. }\end{array}$ & $\begin{array}{l}\text { Chronic } \\
\text { disease } \\
\text { management }\end{array}$ & $\begin{array}{l}\text { Both groups receiving } \\
\text { intervention improved their } \\
\text { quality of life and depression } \\
\text { outcomes. The authors observed } \\
\text { statistically significant changes } \\
\text { in the domain on the SIS and } \\
\text { CES- D Scale except memory } \\
\text { and mood for both groups. The } \\
\text { research findings showed } \\
\text { contraindication to the } \\
\text { hypothesis; the robot assisted } \\
\text { group with home exercises } \\
\text { program showed no significant } \\
\text { improvement in non-motor } \\
\text { outcomes compared to home } \\
\text { exercise group alone. } \\
\text { The authors referred to previous } \\
\text { study done by Studenski (2005), } \\
\text { which consisted of a large } \\
\text { randomized controlled trial } \\
\text { involving repetitive UE tasks } \\
\text { that found expected } \\
\text { improvement in motor domains, } \\
\text { such as upper extremity function } \\
\text { and also improvements in } \\
\text { nonmotor domains, such as } \\
\text { meaningful activities and mood. } \\
\text { Providing telehealth using } \\
\text { robot-assisted rehab post } \\
\text { discharge to stroke patients can } \\
\text { improve QOL and depression }\end{array}$ & $\begin{array}{l}\text { The researchers recognized that } \\
\text { there are only few published } \\
\text { works to support the concept that } \\
\text { rehabilitation after stroke helps } \\
\text { improve recovery, increase } \\
\text { functionality, decrease disability, } \\
\text { and promote reintegration of } \\
\text { patients back to their previous } \\
\text { living condition resulting in a } \\
\text { better quality of life and } \\
\text { stabilization of depression. In } \\
\text { this study, a robot-assisted } \\
\text { device is used plus a home } \\
\text { exercise program. A } \\
\text { recommendation on } \\
\text { incorporating another device, } \\
\text { such as a wrist accelerometer or } \\
\text { to allow better precision on } \\
\text { quantifying compliance by } \\
\text { participants, as well possibly } \\
\text { provide a more objective } \\
\text { explanation of the effects of } \\
\text { various grades of tele } \\
\text { rehabilitation. Lastly, the authors } \\
\text { suggested additional studies to } \\
\text { provide a protocol, which clearly } \\
\text { defines dosing, frequency, and } \\
\text { intensity of home exercise } \\
\text { programs in improving } \\
\text { functionality and affecting } \\
\text { quality of life and depression. }\end{array}$ \\
\hline $\begin{array}{l}\text { Rosen, D., } \\
\text { McCall., \& } \\
\text { Primack, B. } \\
\text { (2017). } \\
\text { Telehealth } \\
\text { protocol to } \\
\text { prevent } \\
\text { readmission } \\
\text { among high-risk }\end{array}$ & $\begin{array}{l}\text { Quantitative } \\
\text { design } \\
\text { LEVEL } 2 \\
\text { high } \\
\text { quality } \\
\text { article }\end{array}$ & $\begin{array}{l}\text { Random sample } \\
\text { of } 50 \text { patients } \\
\text { with congestive } \\
\text { heart failure } \\
\text { (mean age } 61 \\
\text { years) from a } \\
\text { managed care } \\
\text { organization }\end{array}$ & $\begin{array}{l}\text { A telehealth platform } \\
\text { allowing for daily, real-time } \\
\text { reporting of health status } \\
\text { and video conferencing was } \\
\text { developed. Adherence was } \\
\text { defined as the percentage of } \\
\text { days on which the patient } \\
\text { completed the daily check- } \\
\text { in protocol. To assess }\end{array}$ & PDSA model & $\begin{array}{l}\text { Adherence to this telehealth } \\
\text { protocol was excellent and } \\
\text { consistent, even among high- } \\
\text { risk patients. Future research } \\
\text { should test the protocol using a } \\
\text { more rigorous randomized } \\
\text { design. } \\
\text { Congestive heart failure is the } \\
\text { leading cause of hospital }\end{array}$ & $\begin{array}{l}\text { Forty-eight patients }(96 \%) \\
\text { completed the protocol. } \\
\text { Approximately half }(46 \%) \text { were } \\
\text { at high risk for readmission } \\
\text { according to standardized } \\
\text { measures. Median } 120 \text {-day } \\
\text { adherence was } 96 \% \text { and } \\
\text { adherence did not significantly } \\
\text { differ across sex, race, age, }\end{array}$ \\
\hline
\end{tabular}




\begin{tabular}{|c|c|c|c|c|c|c|}
\hline $\begin{array}{l}\text { patients with } \\
\text { congestive heart } \\
\text { failure. American } \\
\text { Journal of } \\
\text { Medicine, 6(11), } \\
1326 .\end{array}$ & & & $\begin{array}{l}\text { efficacy, admission and } \\
\text { readmission rates between } \\
\text { the 6-month intervention } \\
\text { period and the prior } 6 \\
\text { months was compared. }\end{array}$ & & $\begin{array}{l}\text { readmissions. The aim was to } \\
\text { assess adherence and } \\
\text { effectiveness of a telehealth } \\
\text { protocol designed to prevent } \\
\text { hospital admissions for } \\
\text { congestive heart failure. }\end{array}$ & $\begin{array}{l}\text { living situation, depression, } \\
\text { cognitive ability, or risk for } \\
\text { readmission. Half as many } \\
\text { patients were admitted for } \\
\text { congestive heart failure during } \\
\text { the } 6 \text {-month intervention period } \\
\text { compared with the comparison } \\
\text { period }(12 \% \text { vs } 25 \% ; \mathrm{P}=.11) \text {. }\end{array}$ \\
\hline $\begin{array}{l}\text { Strowd, R., Wise, } \\
\text { S., \&Umei, N. } \\
\text { (2014). } \\
\text { Predictors of 30- } \\
\text { day hospital } \\
\text { readmission } \\
\text { following } \\
\text { ischemic and } \\
\text { hemorrhagic } \\
\text { stroke. American } \\
\text { Journal of } \\
\text { Medical Quality, } \\
\text { 30(5), 441-446. }\end{array}$ & $\begin{array}{l}\text { Descriptive } \\
\text { qualitative } \\
\text { method } \\
\text { LEVEL 1 } \\
\text { very high- } \\
\text { quality } \\
\text { article }\end{array}$ & $\begin{array}{l}\text { A total of } 79 \\
\text { cases with acute } \\
\text { ischemic or } \\
\text { hemorrhagic } \\
\text { strokes } \\
\text { readmitted to the } \\
\text { same hospital } \\
\text { within } 30 \text { days } \\
\text { were compared } \\
\text { with } 86 \\
\text { frequency- } \\
\text { matched } \\
\text { controls. }\end{array}$ & $\begin{array}{l}\text { A retrospective case-control } \\
\text { study was designed to } \\
\text { determine factors associated } \\
\text { with } 30 \text {-day readmission } \\
\text { after stroke. }\end{array}$ & Undefined & $\begin{array}{l}\text { Stroke patients have a high rate } \\
\text { of } 30 \text {-day readmission. } \\
\text { Understanding the } \\
\text { characteristics of patients at high } \\
\text { risk of readmission is critical. } \\
\text { Readmitted patients were } \\
\text { associated with history of more } \\
\text { than } \geq 2 \text { hospitalizations in the } \\
\text { year prior to stroke and in the } \\
\text { multivariate model, admission } \\
\text { National Institutes of Health } \\
\text { Stroke Score (NIHSS) }\end{array}$ & $\begin{array}{l}\text { The research team concludes that } \\
\text { admission NIHSS and frequent } \\
\text { prior hospitalizations are } \\
\text { associated with } 30 \text {-day } \\
\text { readmission after stroke. If } \\
\text { validated, these characteristics } \\
\text { identify high-risk patients and } \\
\text { focus efforts to reduce } \\
\text { readmission. }\end{array}$ \\
\hline $\begin{array}{l}\text { Vahidy, F., } \\
\text { Donnelly, J., } \\
\text { McCullough, L., } \\
\text { Tyson, J., Miller, } \\
\text { C., Boehme, A., } \\
\text { Savitz, S. \& } \\
\text { Allbright, K. } \\
\text { (2017). } \\
\text { Nationwide } \\
\text { estimates of 30- } \\
\text { Day readmission } \\
\text { rates in patients } \\
\text { with ischemic } \\
\text { stroke. AHA } \\
\text { Journals, 1386- } \\
\text { 1388. } \\
\text { https://doi.org/10. } \\
\text { 1161/STROKEA } \\
\text { HA.116.01608 }\end{array}$ & $\begin{array}{l}\text { Quantitative } \\
\text { design use of } \\
\text { Survey } \\
\text { design } \\
\text { logistic } \\
\text { regression } \\
\text { models } \\
\text { LEVEL 1 } \\
\text { very high- } \\
\text { quality } \\
\text { article }\end{array}$ & $\begin{array}{l}\text { Sample of } \approx 36 \\
\text { million } \\
\text { discharges from } \\
\text { short-term } \\
\text { hospitals of } 21 \\
\text { geographically } \\
\text { dispersed states in } \\
\text { the United States. }\end{array}$ & $\begin{array}{l}\text { Analysis of the } 2013 \\
\text { Nationwide Readmission } \\
\text { Database to represent all US } \\
\text { hospitalizations. Adult } \\
\text { patients with acute ischemic } \\
\text { stroke, including those who } \\
\text { received intravenous TPA } \\
\text { and intra-arterial therapy, } \\
\text { were identified using ICD-9 } \\
\text { codes. Proportions and 95\% } \\
\text { confidence intervals for } \\
\text { overall 30-day readmissions } \\
\text { and for unplanned and } \\
\text { potentially preventable } \\
\text { readmissions were reported. } \\
\text { Survey design logistic } \\
\text { regression models were fit } \\
\text { for determining crude and } \\
\text { adjusted odds ratios and }\end{array}$ & $\begin{array}{l}\text { Transition of } \\
\text { care }\end{array}$ & $\begin{array}{l}\text { Goal was to provide nationwide } \\
\text { estimates of 30-day readmission } \\
\text { in the United States, identify } \\
\text { reasons for 30-day readmission, } \\
\text { particularly with those who had } \\
\text { recanalization therapy. } \\
\text { Readmitted patients were older } \\
\text { and had a higher comorbidity } \\
\text { burden. After controlling for } \\
\text { age, sex, insurance status, and } \\
\text { comorbidities, patients who } \\
\text { underwent recanalization } \\
\text { therapy had significantly lower } \\
\text { odds of 30-day readmission } \\
\text { (odds ratio, 0.82; 95\% } \\
\text { confidence interval, 0.77-0.89). }\end{array}$ & $\begin{array}{l}\text { Key findings on readmission by } \\
\text { post-discharge day and causes of } \\
\text { readmission showed increase of } \\
12 \% \text { with readmission for those } \\
\text { with recanalization and those } \\
\text { with ischemic stroke for } 30 \text {-day } \\
\text { readmission. } \\
\text { More than } 20 \% \text { of } 30 \text {-day } \\
\text { readmission were due to acute } \\
\text { stroke, followed by septicemia. }\end{array}$ \\
\hline
\end{tabular}




\begin{tabular}{|c|c|c|c|c|c|c|}
\hline & & & $\begin{array}{l}95 \% \text { confidence interval for } \\
\text { association between } \\
\text { recanalization therapy and } \\
\text { 30-day readmission. }\end{array}$ & & & \\
\hline $\begin{array}{l}\text { Bambhroliya, A., } \\
\text { Donnelyu, J., } \\
\text { Tomas, E., } \\
\text { Tyson,J., } \\
\text { Miller,C., } \\
\text { MucCullough, L., } \\
\text { Sa itz, S, } \\
\text { Vahidy,F. (2018). } \\
\text { Estimates and } \\
\text { temporal trends } \\
\text { for US } \\
\text { nationwide } 30 \text { day } \\
\text { hospital } \\
\text { readmission } \\
\text { among patients } \\
\text { with ischemic and } \\
\text { hemorrhagic } \\
\text { stroke. JAMA, } \\
\text { l(4). } \\
\text { Doi:10:1001/jama } \\
\text { netrowrkopem.20 } \\
18.1190\end{array}$ & $\begin{array}{l}\text { Descriptive } \\
\text { qualitative } \\
\text { method as } \\
\text { research } \\
\text { design } \\
\text { LEVEL1 } \\
\text { very high- } \\
\text { quality } \\
\text { article }\end{array}$ & $\begin{array}{l}2 \text { million adult } \\
\text { patients with } \\
\text { stroke nationwide }\end{array}$ & $\begin{array}{l}\text { This study is a population- } \\
\text { based cohort study of the } \\
\text { Nationwide Readmissions } \\
\text { Database between } 2010 \text { and } \\
2015 \text {. This database } \\
\text { represents } 50 \% \text { of all US } \\
\text { hospitalizations from } 22 \\
\text { states. Readmission was } \\
\text { defined as admission within } \\
30 \text { days of discharge from } \\
\text { the hospital. }\end{array}$ & Undefined & $\begin{array}{l}\text { What is the nationwide } \\
\text { proportional change in } 30 \text {-day } \\
\text { hospital readmission among US } \\
\text { patients with ischemic and } \\
\text { hemorrhagic stroke between } \\
2010 \text { and } 2015 \text { ? } \\
\text { Among all patients with stroke, } \\
\text { including intracerebral } \\
\text { hemorrhage, acute ischemic } \\
\text { stroke, and subarachnoid } \\
\text { hemorrhage, } 30 \text {-day readmission } \\
\text { declined by } 3.3 \% \text { from } 2010 \text { to } \\
2015 \text {. }\end{array}$ & $\begin{array}{l}\text { This study did not investigate the } \\
\text { specific reasons for a decrease in } \\
\text { readmission rates, rather it } \\
\text { assessed whether a decrease } \\
\text { existed from } 2010 \text { to } 2015 \text { for } \\
\text { patients who experienced stroke. } \\
\text { More studies should be done to } \\
\text { analyze the specific reasons for } \\
\text { the decrease in readmission rates } \\
\text { in this study. }\end{array}$ \\
\hline $\begin{array}{l}\text { Nouh, A. M., } \\
\text { McCormick, L., } \\
\text { Modak, J., } \\
\text { Fortunato, G., \& } \\
\text { Staff, I. (2017). } \\
\text { High mortality } \\
\text { among 30-day } \\
\text { readmission after } \\
\text { stroke: predictors } \\
\text { and etiologies of } \\
\text { readmission. } \\
\text { Frontiers in } \\
\text { Neurology, } 8, \\
632 . \\
\text { https://doi.org/10. }\end{array}$ & $\begin{array}{l}\text { Descriptive } \\
\text { qualitative } \\
\text { method of a } \\
\text { retrospective } \\
\text { case-control } \\
\text { study } \\
\text { LEVEL 1 } \\
\text { very high- } \\
\text { quality } \\
\text { article }\end{array}$ & $\begin{array}{l}1,544 \text { patients } \\
\text { admitted for } \\
\text { stroke } \\
\text { (hemorrhagic, } \\
\text { ischemic, or TIA) } \\
\text { from January } \\
2013 \text { to } \\
\text { December } 2014 \text {. } \\
\text { Of these, } 134 \\
\text { patients } \\
\text { readmitted within } \\
30 \text { days were } \\
\text { identified as } \\
\text { cases; } 1,418 \text { other } \\
\text { patients, with no }\end{array}$ & $\begin{array}{l}\text { This was a retrospective } \\
\text { case-control study to } \\
\text { identify risk factors } \\
\text { predicting } 30 \text {-day } \\
\text { readmission after stroke. A } \\
\text { descriptive sub-study of the } \\
\text { subset of patients who were } \\
\text { readmitted was also } \\
\text { conducted as was a } \\
\text { mortality analysis of index } \\
\text { and readmissions }\end{array}$ & $\begin{array}{l}\text { Transition of } \\
\text { care model }\end{array}$ & $\begin{array}{l}\text { Although some risk factors for } \\
\text { stroke readmission have been } \\
\text { reported, the mortality risk is } \\
\text { unclear. Researchers sought to } \\
\text { evaluate etiologies and } \\
\text { predictors of } 30 \text {-day } \\
\text { readmissions and determine the } \\
\text { associated mortality risk. } \\
\text { Patients over the age of } 75 \text { who } \\
\text { lived in a facility were more } \\
\text { likely to be readmitted. } \\
\text { Mortality among stroke } \\
\text { readmission is high due to many }\end{array}$ & $\begin{array}{l}\text { Early follow-up for high risk } \\
\text { stroke patients may be beneficial } \\
\text { to prevent readmission and the } \\
\text { associated mortality risks. The } \\
\text { findings recommend that } 30 \text {-day } \\
\text { readmissions in stroke patients } \\
\text { are an occurrence worth } \\
\text { consideration and analysis in } \\
\text { designated stroke } \\
\text { centers/hospitals to design plans } \\
\text { pertaining to post stroke } \\
\text { management. }\end{array}$ \\
\hline
\end{tabular}




\begin{tabular}{|c|c|c|c|c|c|c|}
\hline$\underline{\underline{3389 / \text { fneur.2017. }}} \underline{\underline{00632}}$ & & $\begin{array}{l}\text { readmissions } \\
\text { were identified as } \\
\text { controls }\end{array}$ & & & $\begin{array}{l}\text { factors; readmissions occur } \\
\text { within first } 3 \text { weeks of discharge }\end{array}$ & \\
\hline $\begin{array}{l}\text { O'Connor, M., } \\
\text { Asdornwised, U., } \\
\text { Dempsey, M., } \\
\text { Huffenberger, A., } \\
\text { Jost, S., Norris, } \\
\text { A. (2016). Using } \\
\text { telehealth to } \\
\text { reduce all cause } \\
\text { 30-day hospital } \\
\text { readmissions } \\
\text { among heart } \\
\text { failure patients } \\
\text { receiving skilled } \\
\text { home health } \\
\text { services. Applied } \\
\text { Clinical } \\
\text { Informatics, } 7(2), \\
\text { 238-247. } \\
\underline{\text { http://dx.doi.org/1 }} \\
\underline{0.4338 / A C I-} \\
\underline{2015-11-S O A-} \\
\underline{0157 .}\end{array}$ & $\begin{array}{l}\text { Descriptive } \\
\text { qualitative } \\
\text { method } \\
\text { LEVEL 1 } \\
\text { very high- } \\
\text { quality } \\
\text { article }\end{array}$ & $\begin{array}{l}818 \text { HF patients } \\
\text { at Penn Care at } \\
\text { Home who } \\
\text { received remote } \\
\text { telehealth } \\
\text { monitoring. }\end{array}$ & $\begin{array}{l}\text { Telehealth monitoring is } \\
\text { achieved using the TCM } \\
\text { and incorporates lifestyle } \\
\text { management, patient } \\
\text { education, and consultation } \\
\text { between healthcare } \\
\text { providers to treat patients } \\
\text { virtually. Equipment used } \\
\text { included a monitoring unit } \\
\text { connected to home } \\
\text { landlines, pulse oximeters, } \\
\text { blood pressure devices, } \\
\text { weight scales. Personnel } \\
\text { included two nurses and two } \\
\text { liaisons. }\end{array}$ & $\begin{array}{l}\text { Transition of } \\
\text { Care Model }\end{array}$ & $\begin{array}{l}\text { The re-admission rate for HF } \\
\text { patients at the home health } \\
\text { agency dropped from } 19.3 \% \text { to } \\
14 \% \text { from } 2012 \text { to } 2015 \text { after } \\
\text { employing TCM. In } 2012 \text {, the } \\
\text { telehealth average length of stay } \\
\text { was } 94 \text { days. In } 2015 \text {, the } \\
\text { telehealth average was } 63 \text { days. } \\
\text { For patients who did not receive } \\
\text { telehealth, the re-admission rate } \\
\text { remained the same from } 2012 \text { to } \\
2015 \text { at around } 17.7 \% \text {. }\end{array}$ & $\begin{array}{l}\text { Telehealth through TCM is an } \\
\text { effective model to lower re- } \\
\text { admission rates for patients with } \\
\text { HF. }\end{array}$ \\
\hline $\begin{array}{l}\text { Piette, J., Striplin, } \\
\text { D., Fisher, L., } \\
\text { Aikens, J., Lee, } \\
\text { A., Marinec, N., } \\
\text { \&...Kim, C. } \\
\text { (2019). Effects of } \\
\text { accessible health } \\
\text { technology and } \\
\text { caregiver support } \\
\text { post } \\
\text { hospitalization on } \\
\text { 30-day } \\
\text { readmission risk: } \\
\text { a randomized } \\
\text { trial. The Joint }\end{array}$ & $\begin{array}{l}\text { Descriptive } \\
\text { qualitative } \\
\text { method } \\
\text { LEVEL } 3 \\
\text { low quality } \\
\text { article }\end{array}$ & $\begin{array}{l}283 \text { patients with } \\
\text { common } \\
\text { diagnoses such as } \\
\text { COPD, CAD, } \\
\text { pneumonia, and } \\
\text { diabetes. }\end{array}$ & $\begin{array}{l}\text { IVRs are automated } \\
\text { telephone calls used by } \\
\text { clinicians to follow up with } \\
\text { patients. It is intended to } \\
\text { increase communication } \\
\text { between post-discharge } \\
\text { patients, caregivers, and } \\
\text { clinicians. Patients received } \\
\text { daily IVR calls, up to three } \\
\text { times per day. }\end{array}$ & $\begin{array}{l}\text { Chronic care } \\
\text { Model }\end{array}$ & $\begin{array}{l}\text { The IVR method to increase } \\
\text { communication between post- } \\
\text { discharge patients and clinicians } \\
\text { did not improve overall 30-day } \\
\text { readmission rates. The } \\
\text { readmission rates were roughly } \\
\text { the same between the } \\
\text { intervention and control group. }\end{array}$ & $\begin{array}{l}\text { IVRs are not effective in } \\
\text { reducing } 30 \text {-day readmission. } \\
\text { This could be due to IVRs being } \\
\text { informal and low investment. } \\
\text { Patients are not getting proper } \\
\text { guidance from IVRs to maintain } \\
\text { self-care regimens after } \\
\text { discharge. }\end{array}$ \\
\hline
\end{tabular}




\begin{tabular}{|l|l|l|l|l|l|}
\hline Commission & & & & \\
Journal on & & & & \\
Quality and & & & & \\
Patient Safety, 46, & & & & \\
$109-117$. & & & \\
http://doi.org/10.1 & & & & & \\
$\underline{\underline{016 / j . j c j q .2019 .10}}$ & & & & & \\
\hline
\end{tabular}

Legend: (CME, Caregiver- mediated exercise; SIS, Stroke Impact Scale; ADL, Activities of Daily Living; PAH, Potential Avoidable Hospitalization; AMDA, American Medical Director Association; SD, Standard Deviation; PCOC, Palliative Care Outcomes Collaboration; QOL, Quality of life; CES-D, Center for Epidemiologic Studies Depression; SORT, Strength of Recommendation Taxonomy, TCM, Transition Care Model; IVR, Interactive Voice Response, NIHSS, National Institutes of Health Stroke Score) 


\section{Appendix B}

SWOT ANALYSIS for Agency

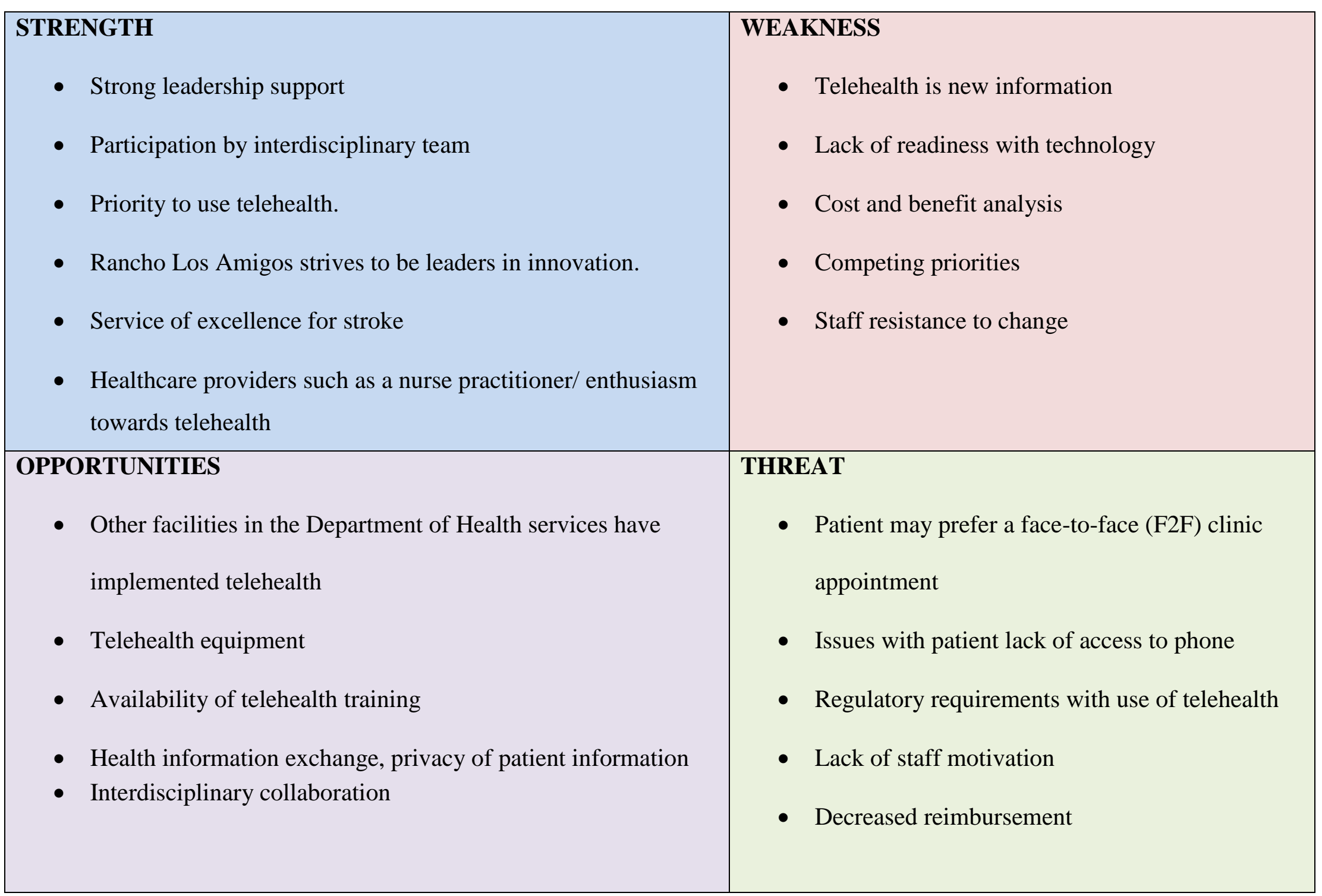




\section{Appendix C}

Training Flyer and Sign-in Sheet
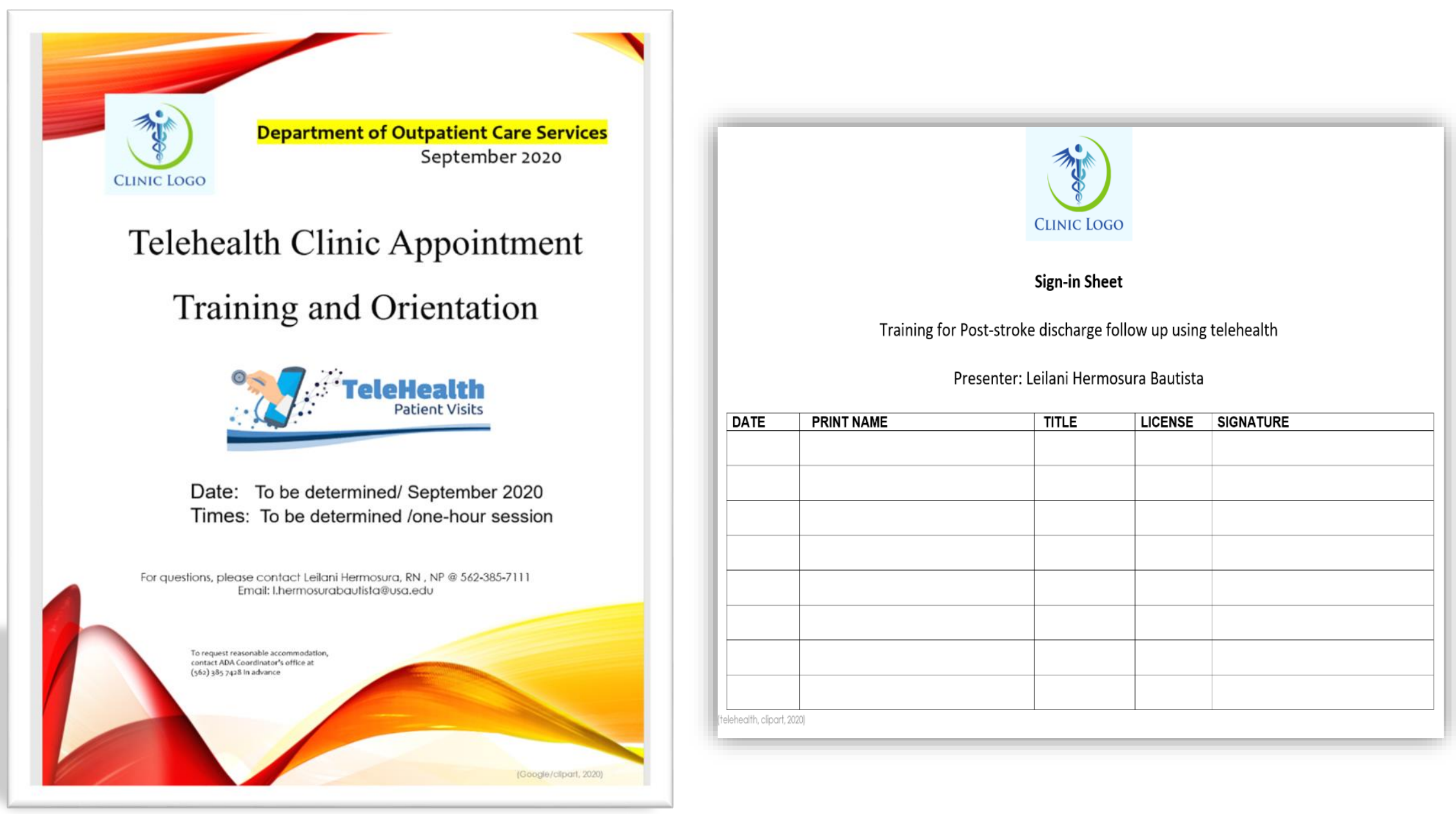
Appendix D

Telehealth Power Point Presentation

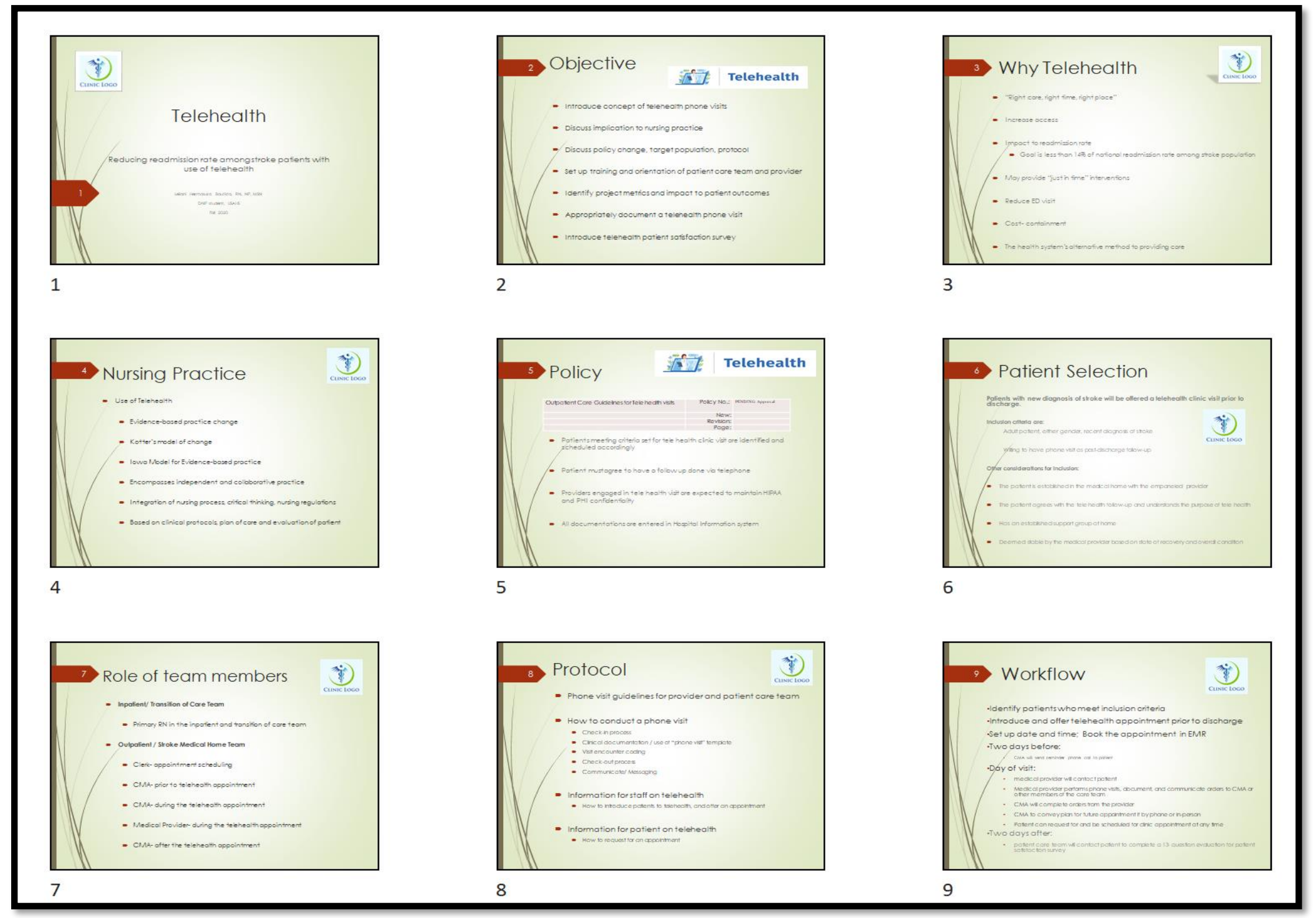




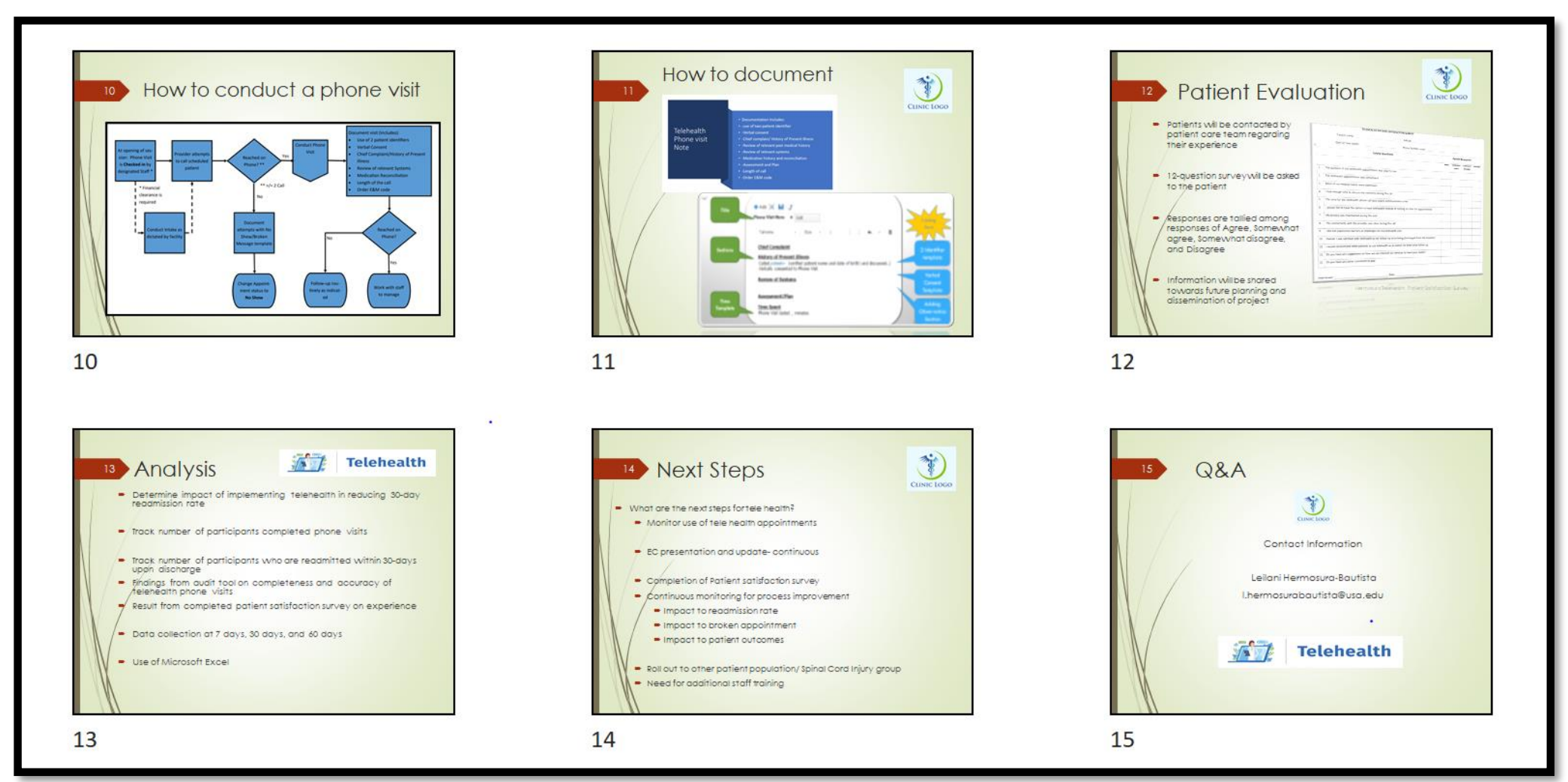




\section{Appendix E}

Telephone visit Guideline (handout)

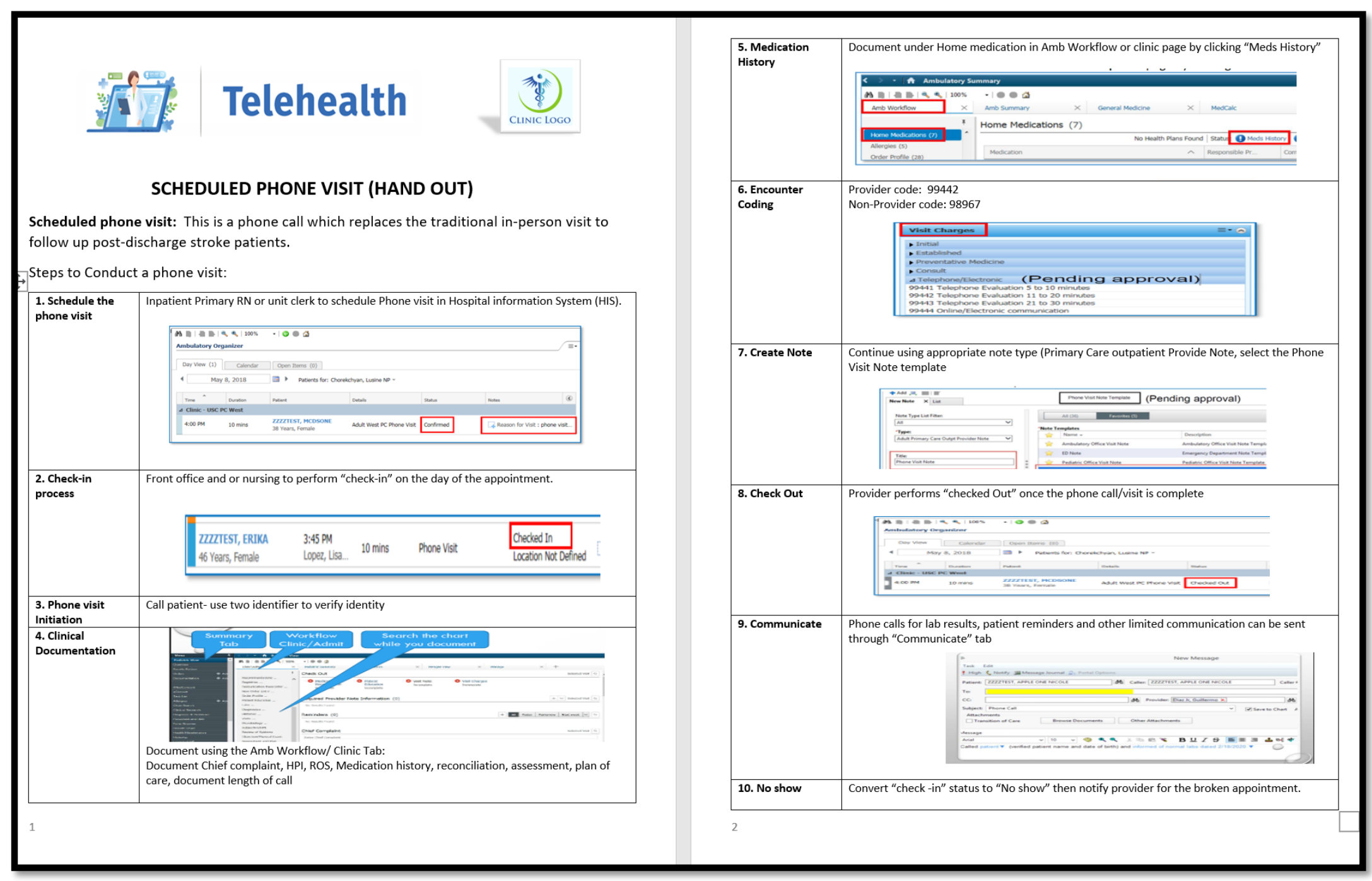


Appendix F

Telehealth Phone Visit Documentation

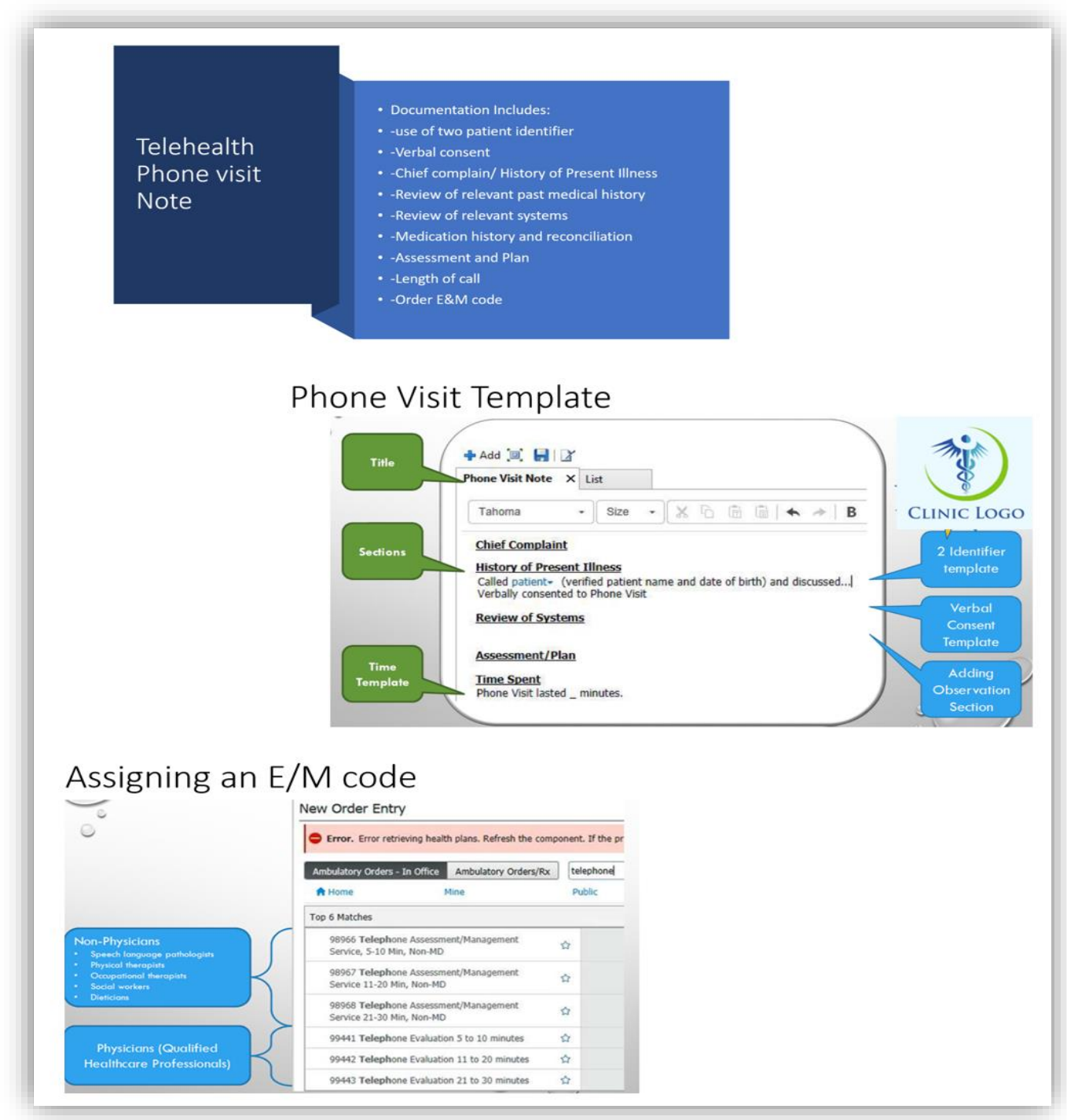




\section{Appendix G}

Employee Guideline on Telehealth Phone Visit

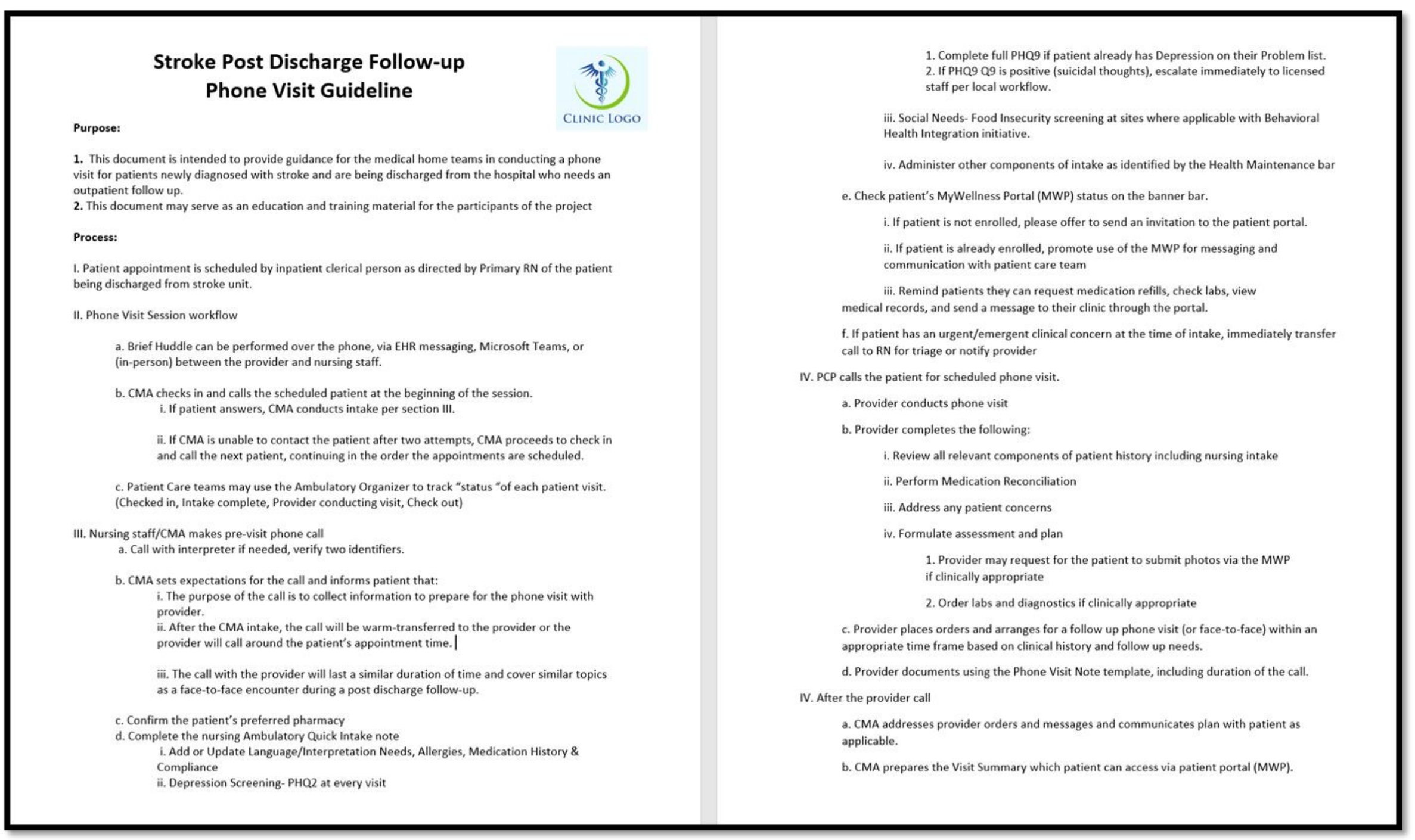




\section{Appendix H}

Patient Information on Telehealth Phone Visit

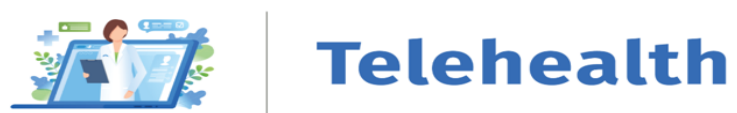

USE OF TELEHEALTH FOR YOUR FOLOW UP APPOINTMENT AFTER DISCHARGE

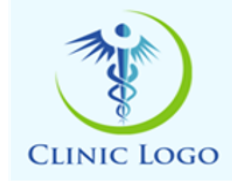

Dear patient,

For your comfort and convenience, we are now offering telehealth phone clinic appointment to patients who are being discharged from the hospital. This replaces the in-person clinic appointment.

If you are interested, please inform your medical provider or your primary patient care team and we can set up an appointment for you.

Here are what you need to know:

- Your medical care is at your fingertip!

- Request a telehealth visit through your patient care team prior to discharge

- Phone visits are treated the same as any other in-person visit and are scheduled as an appointment with the medical provider

- During the telehealth phone visit, the medical provider will discuss with you:

$\checkmark$ Update to your medical condition since your discharge

$\checkmark$ Review and refill your medications or medical supplies and equipment

$\checkmark$ Determine if any additional lab work or diagnostic exam will be performed

$\checkmark$ Referrals to any specialty services if necessary

$\checkmark$ Introduce you to the patient care team working with your medical provider

$\checkmark$ How to make future appointments, in-person or by telehealth

$\checkmark$ How to leave messages with the Nurse Call Center

- By signing below, you are interested in receiving a telehealth phone visit for your follow up. Please inform your patient care team so that an appointment can be set up for you.

- NAME: Signed by Patient

- PHONE: 123-456-7890

- DATE: ___ October,|2020 


\section{Appendix I}

Project Timeline Schedule

\begin{tabular}{|c|c|c|c|c|c|c|c|c|c|c|c|c|c|c|c|c|c|c|c|c|c|c|c|c|}
\hline & \multicolumn{8}{|c|}{ NUR7801 } & \multicolumn{8}{|c|}{ NUR7802 } & \multicolumn{8}{|c|}{ NUR7803 } \\
\hline 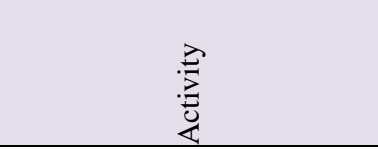 & $\begin{array}{l}\frac{y}{1} \\
\frac{d}{3}\end{array}$ & $\begin{array}{l}\frac{m}{1} \\
\frac{1}{3} \\
3\end{array}$ & $\begin{array}{l}n \\
\frac{n}{0} \\
3 \\
3\end{array}$ & $\begin{array}{l}\frac{1}{0} \\
\frac{1}{3}\end{array}$ & $\begin{array}{l}\frac{a}{d} \\
\frac{0}{3}\end{array}$ & $\begin{array}{l}= \\
\frac{y}{8} \\
3\end{array}$ & $\begin{array}{l}\frac{m}{2} \\
\frac{x}{d} \\
\frac{d}{3}\end{array}$ & $\frac{n}{\frac{n}{d}}$ & $\begin{array}{l}\frac{7}{2} \\
\frac{4}{0} \\
3\end{array}$ & $\begin{array}{l}\frac{n}{d} \\
\frac{0}{3}\end{array}$ & $\begin{array}{l}n \\
\frac{n}{j} \\
3\end{array}$ & $\frac{\sqrt[y]{2}}{3}$ & $\begin{array}{l}\hat{\ddot{y}} \\
\frac{\ddot{d}}{3}\end{array}$ & $\begin{array}{l}= \\
\frac{\pi}{8} \\
3\end{array}$ & $\begin{array}{l}m \\
\frac{n}{0} \\
3 \\
3\end{array}$ & $\begin{array}{l}\frac{n}{3} \\
\frac{\pi}{0} \\
3\end{array}$ & $\begin{array}{l}\bar{y} \\
\frac{y}{8} \\
3\end{array}$ & $\begin{array}{l}m \\
\frac{v}{d} \\
\dot{d} \\
3\end{array}$ & $\begin{array}{l}n \\
\frac{\pi}{\Xi} \\
3\end{array}$ & $\frac{5}{8}$ & $\frac{a}{y}$ & $\begin{array}{l}z \\
\frac{y}{j} \\
\sum_{3}^{0}\end{array}$ & $\begin{array}{l}\frac{m}{2} \\
\frac{\pi}{0} \\
\frac{d}{3}\end{array}$ & $\begin{array}{l}\frac{n}{4} \\
\frac{\pi}{2} \\
\frac{8}{3}\end{array}$ \\
\hline PROJECT PLANNING & & & & & & & & & & & & & & & & & & & & & & & & \\
\hline Meet with preceptor & $\mathbf{X}$ & & & & & & & & & & & & & & & & & & & & & & & \\
\hline $\begin{array}{l}\text { Identify issues and gaps at } \\
\text { RLA clinics }\end{array}$ & $\mathrm{X}$ & & & & & & & & & & & & & & & & & & & & & & & \\
\hline Review literature & $\mathbf{X}$ & $\mathbf{X}$ & $\mathbf{X}$ & & & & & & & & & & & & & & & & & & & & & \\
\hline Prepare project proposal & & $\mathbf{X}$ & $\mathbf{X}$ & $\mathbf{X}$ & & & & & & & & & & & & & & & & & & & & \\
\hline $\begin{array}{l}\text { Discuss with executive } \\
\text { leadership regarding } \\
\text { proposal }\end{array}$ & & & $\mathbf{X}$ & $\mathbf{X}$ & $\mathbf{X}$ & & & & & & & & & & & & & & & & & & & \\
\hline $\begin{array}{l}\text { Identify key stakeholders } \\
\text { and work with them } \\
\text { regarding project charter and } \\
\text { scope }\end{array}$ & $\mathbf{X}$ & $\mathbf{X}$ & & & & & & & & & & & & & & & & & & & & & & \\
\hline $\begin{array}{l}\text { Identify nursing resources } \\
\text { for the project }\end{array}$ & & $\mathbf{X}$ & $\mathbf{X}$ & & & & & & & & & & & & & & & & & & & & & \\
\hline Identify provider support & & $\mathbf{X}$ & $\mathbf{X}$ & & & & & & & & & & & & & & & & & & & & & \\
\hline $\begin{array}{l}\text { Develop workflow for } \\
\text { telehealth visit }\end{array}$ & & & & & & $\mathbf{X}$ & $\mathbf{X}$ & & & & & & & & & & & & & & & & & \\
\hline $\begin{array}{l}\text { Develop policy and } \\
\text { procedure }\end{array}$ & & & & & & $\mathbf{X}$ & $\mathbf{X}$ & $\mathbf{X}$ & & & & & & & & & & & & & & & & \\
\hline Identify equipment request & & $\mathbf{X}$ & $\mathbf{X}$ & $\mathbf{X}$ & $\mathbf{X}$ & & & & & & & & & & & & & & & & & & & \\
\hline Identify go-live date & & & & & & & & $\mathbf{X}$ & & & & & & & & & & & & & & & & \\
\hline $\begin{array}{l}\text { Acquire organization IRB } \\
\text { approval }\end{array}$ & & & & & & & & $\mathbf{X}$ & & & & & & & & & & & & & & & & \\
\hline $\begin{array}{l}\text { LOGISTICAL } \\
\text { PLANNING } \\
\end{array}$ & & & & & & & & & & & & & & & & & & & & & & & & \\
\hline $\begin{array}{l}\text { Add standard consent } \\
\text { process and patient privacy }\end{array}$ & & & & & & & & $\mathbf{X}$ & $\mathbf{X}$ & & & & & & & & & & & & & & & \\
\hline Develop training materials & & & & & & & & $\mathbf{X}$ & $\mathbf{X}$ & & & & & & & & & & & & & & & \\
\hline $\begin{array}{l}\text { Develop a standardized } \\
\text { clinician guidelines }\end{array}$ & & & & & & & & & $\mathbf{X}$ & $\mathbf{X}$ & & & & & & & & & & & & & & \\
\hline identify telehealth & & & & & & & & & & $\mathrm{X}$ & $\mathrm{X}$ & & & & & & & & & & & & & \\
\hline
\end{tabular}


REDUCING STROKE READMISSION

\begin{tabular}{|c|c|c|c|c|c|c|c|c|c|c|c|c|c|c|c|c|c|c|c|c|c|c|c|c|}
\hline & \multicolumn{8}{|c|}{ NUR7801 } & \multicolumn{8}{|c|}{ NUR7802 } & \multicolumn{8}{|c|}{ NUR7803 } \\
\hline 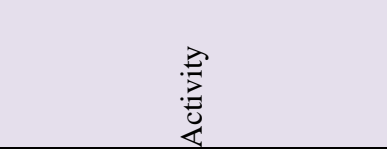 & $\begin{array}{l}\vec{y} \\
\bar{u} \\
3\end{array}$ & $\begin{array}{l}m \\
\frac{y}{d} \\
z\end{array}$ & $\begin{array}{l}n \\
\frac{u}{d} \\
\dot{d}\end{array}$ & $\begin{array}{l}\frac{\pi}{0} \\
\frac{0}{3} \\
3\end{array}$ & $\begin{array}{l}\frac{a}{y} \\
\frac{u}{3}\end{array}$ & $\begin{array}{l}= \\
\frac{y}{d} \\
3\end{array}$ & $\begin{array}{l}\frac{m}{3} \\
\frac{\pi}{0} \\
3\end{array}$ & $\begin{array}{l}\frac{n}{2} \\
\frac{y}{d} \\
3\end{array}$ & $\begin{array}{l}\bar{y} \\
\frac{0}{0} \\
3\end{array}$ & $\begin{array}{l}m \\
\frac{n}{0} \\
z \\
3\end{array}$ & $\begin{array}{l}n \\
\frac{n}{d} \\
z \\
z\end{array}$ & $\begin{array}{l}\bar{y} \\
\frac{y}{d} \\
3\end{array}$ & $\begin{array}{l}a \\
\frac{y}{d} \\
z\end{array}$ & $\begin{array}{l}= \\
\bar{u} \\
\vec{z}\end{array}$ & $\begin{array}{l}\frac{m}{\Delta} \\
\frac{u}{0} \\
3\end{array}$ & $\begin{array}{l}\frac{n}{2} \\
\frac{y}{0} \\
3\end{array}$ & $\begin{array}{l}\vec{y} \\
\frac{u}{0} \\
3\end{array}$ & $\begin{array}{l}m \\
\frac{n}{0} \\
\overrightarrow{3}\end{array}$ & $\begin{array}{l}n \\
\frac{n}{8} \\
0 \\
3\end{array}$ & $\begin{array}{l}\frac{\pi}{8} \\
\frac{0}{3}\end{array}$ & $\begin{array}{l}a \\
\frac{y}{d} \\
0 \\
3\end{array}$ & $\begin{array}{l}= \\
\frac{y}{d} \\
3\end{array}$ & $\begin{array}{l}\frac{m}{y} \\
\frac{u}{d} \\
\sum^{0}\end{array}$ & $\begin{array}{l}\frac{n}{4} \\
\frac{\pi}{d} \\
3\end{array}$ \\
\hline workstation & & & & & & & & & & & & & & & & & & & & & & & & \\
\hline $\begin{array}{l}\text { Identify office space and } \\
\text { designated work station }\end{array}$ & & & & & & & & & & & $\mathbf{X}$ & $\mathbf{X}$ & & & & & & & & & & & & \\
\hline $\begin{array}{l}\text { Orient and review telehealth } \\
\text { technology for education and } \\
\text { IT development }\end{array}$ & & & & & & & & & & & $\mathbf{X}$ & $\mathbf{X}$ & & & & & & & & & & & & \\
\hline $\begin{array}{l}\text { Work with IT for technical } \\
\text { readiness and technology } \\
\text { testing }\end{array}$ & & & & & & & & & & $\mathbf{X}$ & $\mathbf{X}$ & & & & & & & & & & & & & \\
\hline $\begin{array}{l}\text { Identify equipment and } \\
\text { devices needed }\end{array}$ & & & & & & & & & $\mathbf{X}$ & $\mathbf{X}$ & & & & & & & & & & & & & & \\
\hline Create Clinic documentation & & & & & & & $\mathbf{X}$ & $\mathbf{X}$ & $\mathrm{X}$ & & & & & & & & & & & & & & & \\
\hline Test Clinic documentation & & & & & & & $\mathbf{X}$ & $\mathbf{X}$ & $\mathbf{X}$ & & & & & & & & & & & & & & & \\
\hline $\begin{array}{l}\text { EHR access and system } \\
\text { review training }\end{array}$ & & & & & & & & $\mathrm{X}$ & $\mathbf{X}$ & & & & & & & & & & & & & & & \\
\hline $\begin{array}{l}\text { Identify clinic provider and } \\
\text { nursing team }\end{array}$ & & & $\mathbf{X}$ & $\mathbf{X}$ & & & & & & & & & & & & & & & & & & & & \\
\hline $\begin{array}{l}\text { PROJECT } \\
\text { IMPLEMENTATION }\end{array}$ & & & & & & & & & & & & & & & & & & & & & & & & \\
\hline $\begin{array}{l}\text { Confirm approval from } \\
\text { EBPC, NEC from USAHS } \\
\text { and budget approval }\end{array}$ & & & & & & & $\mathbf{X}$ & $\mathbf{X}$ & & & & & & & & & & & & & & & & \\
\hline $\begin{array}{l}\text { Set project meetings weekly } \\
\text { to track progress and make } \\
\text { adjustments }\end{array}$ & & & & & & & & & $\mathbf{X}$ & $\mathbf{X}$ & & & & & & & & & & & & & & \\
\hline $\begin{array}{l}\text { Training Appointment center } \\
\text { for patient scheduling }\end{array}$ & & & & & & & & & & $\mathbf{X}$ & $\mathbf{X}$ & & & & & & & & & & & & & \\
\hline $\begin{array}{l}\text { Training for patient or } \\
\text { caregiver }\end{array}$ & & & & & & & & & & $\mathbf{X}$ & $\mathbf{X}$ & & & & & & & & & & & & & \\
\hline $\begin{array}{l}\text { Documentation training for } \\
\text { telehealth }\end{array}$ & & & & & & & & & & & $\mathbf{X}$ & $\mathbf{X}$ & & & & & & & & & & & & \\
\hline $\begin{array}{l}\text { Celebrate project successful } \\
\text { start up }\end{array}$ & & & & & & & & & & & & $\bar{X}$ & & & & & & & & & & & & \\
\hline Project kick-off & & & & & & & & & & & & $\mathrm{X}$ & $\mathrm{X}$ & & & & & & & & & & & \\
\hline $\begin{array}{l}\text { Make adjustment to project } \\
\text { as needed }\end{array}$ & & & & & & & & & & & & & & & $\mathbf{X}$ & & & & & & & & & \\
\hline $\begin{array}{l}\text { DATA COLLECTION } \\
\text { AND ANALYSIS }\end{array}$ & & & & & & & & & & & & & & & & & & & & & & & & \\
\hline Baseline data collection & & & & & & & & & & & & & & & $\mathbf{X}$ & $\mathbf{X}$ & $\mathbf{X}$ & & & & & & & \\
\hline
\end{tabular}


REDUCING STROKE READMISSION

\begin{tabular}{|c|c|c|c|c|c|c|c|c|c|c|c|c|c|c|c|c|c|c|c|c|c|c|c|c|}
\hline & \multicolumn{8}{|c|}{ NUR7801 } & \multicolumn{8}{|c|}{ NUR7802 } & \multicolumn{8}{|c|}{ NUR7803 } \\
\hline 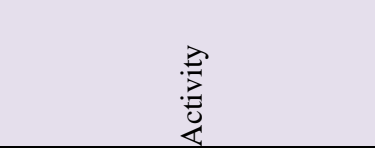 & $\begin{array}{l}\bar{y} \\
\bar{d} \\
3\end{array}$ & $\frac{n}{\frac{n}{d}}$ & $\begin{array}{l}n \\
\frac{y}{d} \\
z \\
3\end{array}$ & $\begin{array}{l}\frac{\pi}{8} \\
\frac{0}{3}\end{array}$ & 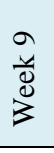 & $\begin{array}{l}= \\
\bar{u} \\
\bar{u} \\
z\end{array}$ & $\begin{array}{l}\frac{m}{v} \\
\frac{\pi}{d} \\
3\end{array}$ & $\begin{array}{l}\frac{n}{\pi} \\
\frac{\pi}{d} \\
3\end{array}$ & $\begin{array}{l}\bar{y} \\
\frac{\pi}{3} \\
3\end{array}$ & $\begin{array}{l}m \\
\ddot{0} \\
0 \\
3\end{array}$ & $\begin{array}{l}n \\
\frac{n}{0} \\
3 \\
3\end{array}$ & $\begin{array}{l}\frac{\pi}{0} \\
\frac{0}{3} \\
3\end{array}$ & $\begin{array}{l}\frac{a}{\Delta} \\
\frac{\pi}{3}\end{array}$ & $\begin{array}{l}\exists \\
\ddot{u} \\
\bar{u}\end{array}$ & $\begin{array}{l}\frac{m}{\Delta} \\
\frac{\pi}{3}\end{array}$ & $\begin{array}{l}n \\
\frac{\pi}{d} \\
3\end{array}$ & $\begin{array}{l}\bar{y} \\
\frac{1}{0} \\
3\end{array}$ & $\begin{array}{l}m \\
\frac{v}{d} \\
z\end{array}$ & $\begin{array}{l}n \\
\frac{1}{0} \\
3 \\
3\end{array}$ & $\frac{5}{\frac{1}{8}}$ & $\begin{array}{l}a \\
\frac{a}{0} \\
3\end{array}$ & $\begin{array}{l}= \\
\frac{\pi}{8} \\
0 \\
3\end{array}$ & $\begin{array}{l}\frac{m}{y} \\
\frac{y}{d} \\
\frac{d}{3}\end{array}$ & $\begin{array}{l}\frac{n}{4} \\
\frac{\pi}{d} \\
3\end{array}$ \\
\hline needs to be included. & & & & & & & & & & & & & & & & & & & & & & & & \\
\hline $\begin{array}{l}30 \text { day and } 60 \text {-day collection } \\
\text { and report }\end{array}$ & & & & & & & & & & & & & & & & & $\mathbf{X}$ & $\mathrm{x}$ & & & & & & \\
\hline Data analysis and reporting & & & & & & & & & & & & & & & & $\mathbf{X}$ & $\mathbf{X}$ & $\mathrm{x}$ & & & & & & \\
\hline $\begin{array}{l}\text { Process measures to be } \\
\text { collected at least weekly and } \\
\text { to include audit or } \\
\text { surveillance }\end{array}$ & & & & & & & & & & & & & & & & & & $\mathrm{X}$ & $\mathbf{X}$ & $\mathbf{X}$ & & & & \\
\hline $\begin{array}{l}\text { Share with frontline team } \\
\text { progress }\end{array}$ & & & & & & & & & & & & & & & & & & & & & $\mathbf{X}$ & $\mathbf{X}$ & & \\
\hline $\begin{array}{l}\text { Give feedback to staff to } \\
\text { improve the fidelity of your } \\
\text { proposed change in practice. }\end{array}$ & & & & & & & & & & & & & & & & & & & & & $\mathbf{X}$ & $\mathbf{X}$ & & \\
\hline $\begin{array}{l}\text { Share with stakeholder the } \\
\text { progress }\end{array}$ & & & & & & & & & & & & & & & & & & & & & $\mathbf{X}$ & $\mathbf{X}$ & & \\
\hline $\begin{array}{l}\text { Share progress with } \\
\text { leadership at management } \\
\text { council }\end{array}$ & & & & & & & & & & & & & & & & & & & & & & $\mathbf{X}$ & $\mathbf{X}$ & \\
\hline $\begin{array}{l}\text { Compare data to expected } \\
\text { outcome with nurse } \\
\text { informaticist }\end{array}$ & & & & & & & & & & & & & & & & & & & & & & $\mathbf{X}$ & & \\
\hline $\begin{array}{l}\text { Evaluate staff compliance } \\
\text { throughout implementation }\end{array}$ & & & & & & & & & & & & & & & & & & & & & & $\mathbf{X}$ & & \\
\hline $\begin{array}{l}\text { Submit report to school and } \\
\text { Include faculty approvals } \\
\text { and presentations to different } \\
\text { groups }\end{array}$ & & & & & & & & & & & & & & & & & & & & & & & $\mathbf{X}$ & \\
\hline $\begin{array}{l}\text { Celebrate with staff and } \\
\text { recognize hard work }\end{array}$ & & & & & & & & & & & & & & & & & & & & & & & & $\mathbf{X}$ \\
\hline & & & & & & & & & & & & & & & & & & & & & & & & \\
\hline
\end{tabular}




\section{Appendix J}

Evaluation Plan

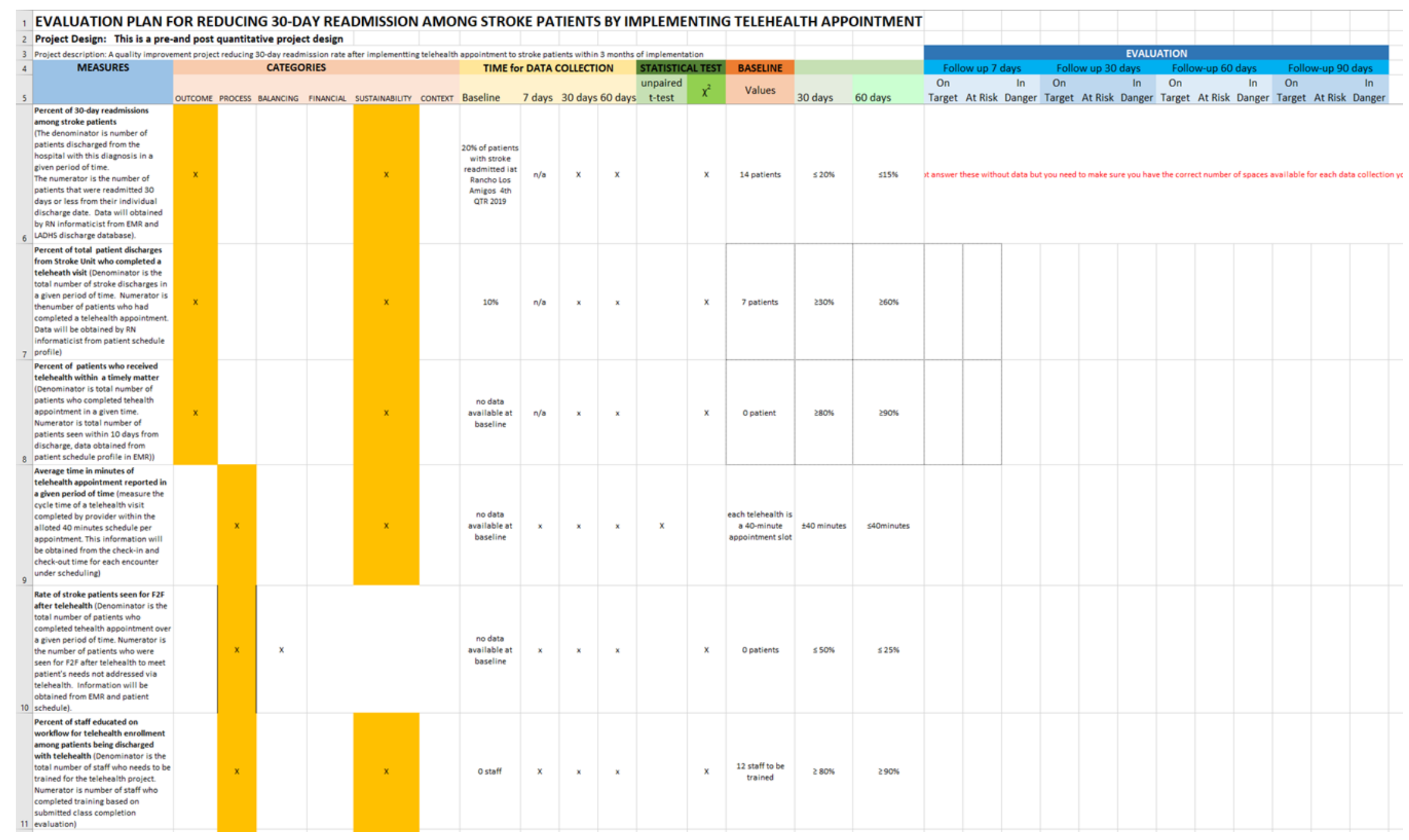




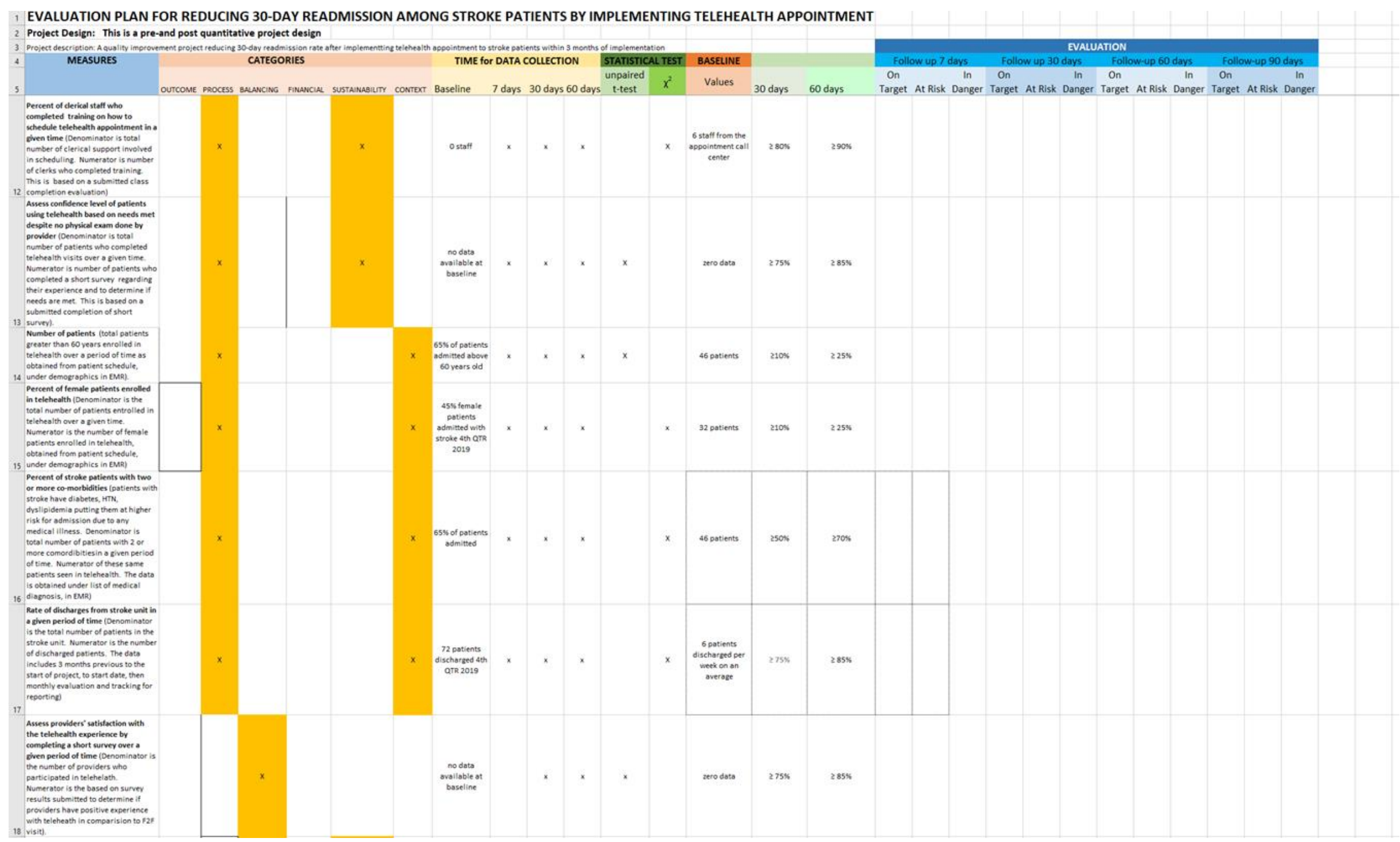




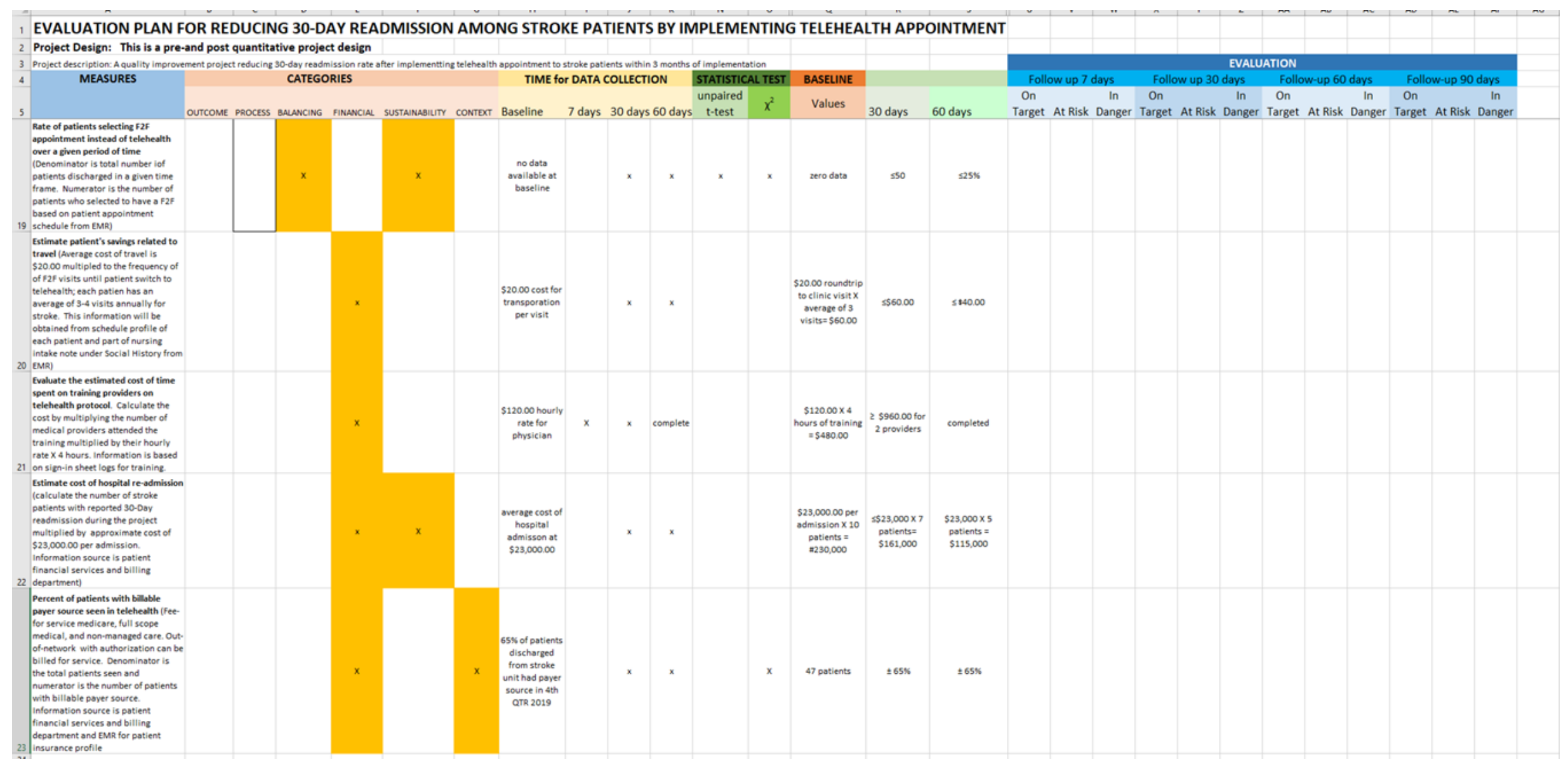




\section{Appendix K}

Audit Tool to Assess Completeness and Accuracy of Telehealth Phone Visit

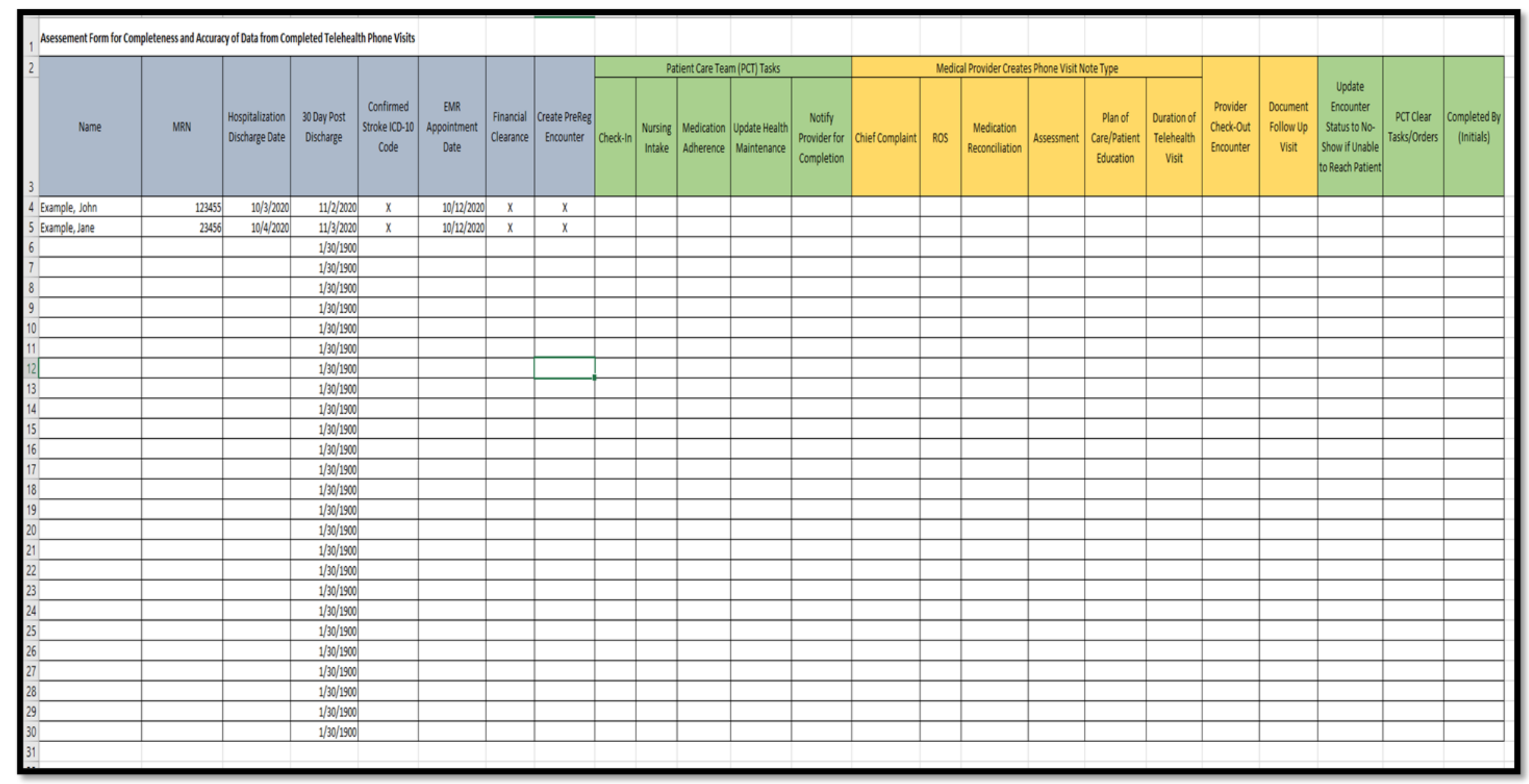


Appendix L

Patient Experience Survey Evaluation Tool

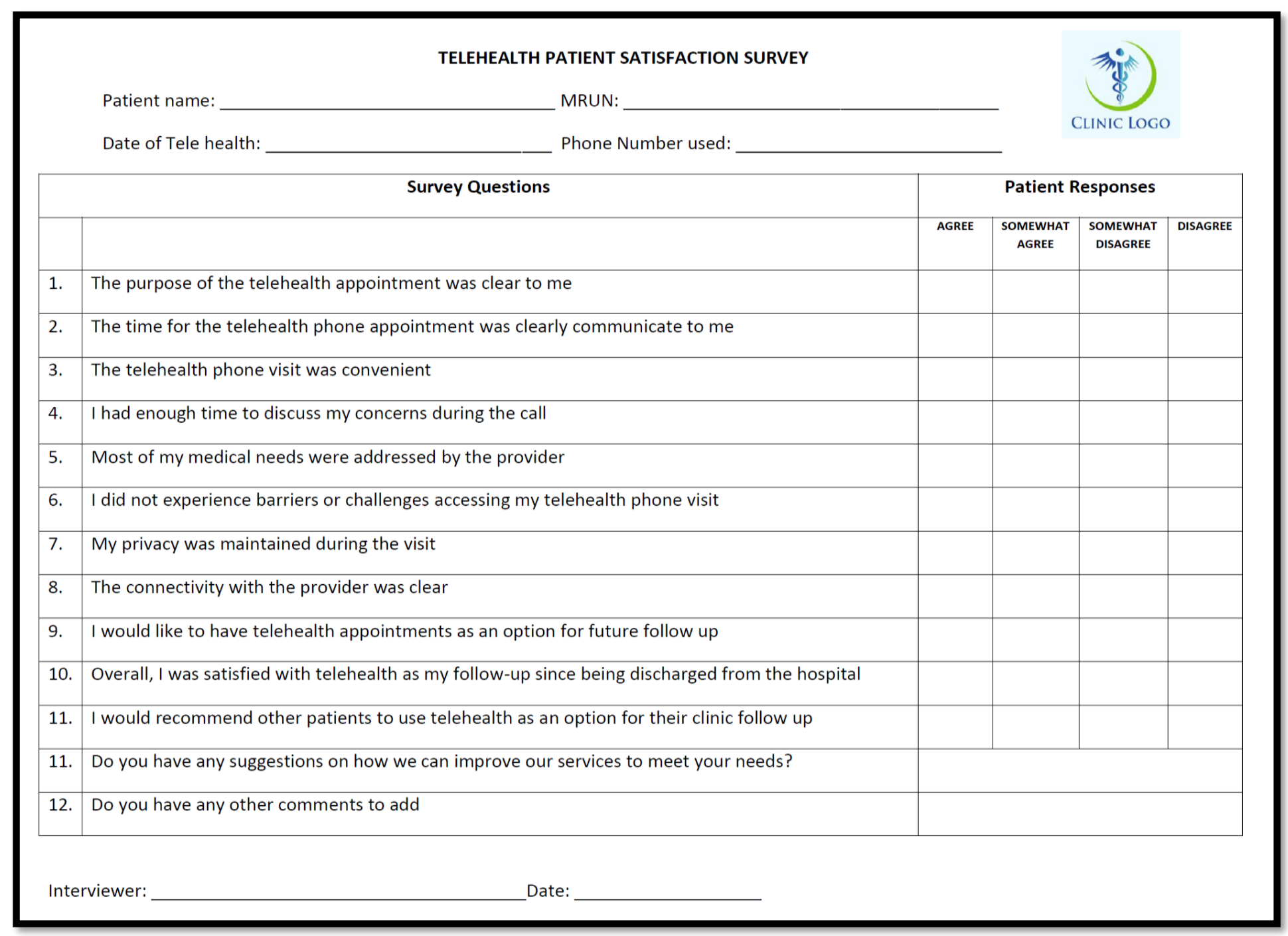

